This item was submitted to Loughborough's Research Repository by the author.

Items in Figshare are protected by copyright, with all rights reserved, unless otherwise indicated.

\title{
Selective laser melting using holographic beam manipulation: influence of polypropylene molecular weight
}

PLEASE CITE THE PUBLISHED VERSION

http://dx.doi.org/10.1108/RPJ-08-2016-0134

\section{PUBLISHER}

(C) Emerald

VERSION

AM (Accepted Manuscript)

\section{PUBLISHER STATEMENT}

This work is made available according to the conditions of the Creative Commons Attribution-NonCommercialNoDerivatives 4.0 International (CC BY-NC-ND 4.0) licence. Full details of this licence are available at: https://creativecommons.org/licenses/by-nc-nd/4.0/

\section{LICENCE}

CC BY-NC-ND 4.0

\section{REPOSITORY RECORD}

Haworth, Barry, John R. Tyrer, and Zhou Zhou. 2017. "Selective Laser Melting Using Holographic Beam Manipulation: Influence of Polypropylene Molecular Weight". figshare. https://hdl.handle.net/2134/24264. 


\title{
Selective Laser Melting using Holographic Beam Manipulation: Influence of Polypropylene Molecular Weight
}

\begin{abstract}
Purpose - There is a requirement to match selective laser melting (SLM) technologies to a wider range of polymeric materials, since the existing market for SLM powders is dominated by polyamide PA12. Drivers include the tailoring of physical properties to individual applications, or cost reduction. Polypropylene (PP) currently has limited use in SLM, so the potential use of PP materials of varying molecular weight (Mw) is explored here.

Design I methodology I approach - PP polymers of differing molecular weight were characterised using a range of analytical techniques, including DSC, thermogravimetric analysis (TGA), rotational rheometry and real-time hot-stage (optical) microscopy.

Findings - The techniques are sufficiently sensitive to distinguish molecular weight effects, notably in terms of material viscosity. The stable sintering region for SLM has been defined clearly. Some success was achieved in melting parts using some grades of PP, including higher molecular weight grades, which potentially offer improved mechanical performance.

Research limitations I implications - The range of techniques (DSC, OIT and TGA) form an effective analytical package with which to consider new polymeric materials for SLM.

Practical implications - High-MW PP polymers, in tape or powder form, have potential use in SLM processes, providing scope to enhance part properties in future.

Originality I value - This is believed to be the first in-depth study noting the influence of PP molecular weight on important physical performance in a proprietary SLM process, using holographic beam manipulation (HBM).
\end{abstract}

Keywords: Laser melting / plastics / thermal characterisation / polypropylene / molecular weight

Paper type: Research paper 


\section{Introduction}

In the modern manufacturing sector, innovation, complex product design and cost reduction are important challenges (Yan and $\mathrm{Gu}, 1996$ ). Conventional manufacturing techniques such as injection moulding and extrusion offer exceptional opportunity for the manufacture of polymer-based products yet will not always meet future objectives, so that the range of Additive Manufacturing (AM) techniques represents new technologies of increased importance for future part design and manufacture (Levy et al, 2003). AM uses computeraided design (CAD) techniques to build products in three-dimensions (3D), using additive, multi-layer technologies that offer complete design freedom and do not require expensive tooling (Goodridge et al., 2012). Complex geometries of products including cellular structures can be achieved using AM (Chu et al., 2008), a convenient technology set that can be used in manufacture, or in the home to create models and other simple articles. AM is being used increasingly to create prototypes and manufactured parts in a wide range of commercial sectors including aerospace, automotive, packaging and also biomedical components, including teeth, bones and implants which need special design and customisation from patients (Levy et al., 2003). Selective laser melting (SLM) is widely used in AM; during this process, the material is selectively melted by laser power to form parts of pre-defined dimensions, then consolidates within a cooling phase (usually on a heated bed) so that the melted product is built layer by layer until the whole structure is completed. As the process 'build' proceeds, un-melted powder material around the product supports the structures (Goodridge et al., 2012). The theoretical understanding of these processes has developed rapidly in recent years, yet there are many challenges to overcome, including the requirements to achieve more consistent and reliable physical properties, enhanced surface finish and to increase the range of materials which can be used successfully in the process.

\subsection{Materials selection for Laser Melting Processes}

Several critical parameters exist when operating conventional laser melting processes, including energy density, which influences the physical and mechanical properties of melted parts (Gibson and Shi, 1997; Caulfield et al., 2007) and is determined by laser power, scanning speed and scan spacing. Energy density is given by (Goodridge et al., 2012; Lu and $\mathrm{Fu}, 2001)$ :

$$
U_{A}=\frac{P}{y \cdot v_{b}} \quad\left(\text { in } \mathrm{J} \mathrm{mm}^{-2}\right)
$$

$\mathrm{P}$ is laser power, $\mathrm{y}$ is scan spacing and $\mathrm{v}_{\mathrm{b}}$ is laser scan / beam speed. 
Optimum choice of energy density is material and process-specific but in principle, low energy density creates porous and weak products due to incomplete melting and poor inter-particle bonding, whilst high energy density may result in excessively high temperature during SLM processing, allowing chemical degradation to take place. As an extension to this approach, the magnitude of energy density emitted by the laser relative to the theoretical energy required to melt the material has been expressed by an energy melt ratio (EMR) parameter (Starr et al., 2011). Subsequently, a theoretical approach using the Kissinger technique (based upon energy melt ratio data) has been proposed to define upper temperature limits in laser melting PA12 more precisely (Vasquez et al., 2013). Mechanical properties of melted parts, using any polymer types, are likely to be optimised within the stable melting region (Vasquez et al., 2011), but before the upper temperature limit. In conventional laser melting, polymer powders need to be pre-heated before being melted and thermal energy is provided by a powder bed, usually held at a temperature below the melting point $\left(T_{m}\right)$ of semi-crystalline polymers. Bed temperature is also important in solidification, to help avoid shrinkage and distortion which may occur if thermal gradients are excessive during cooling (Shi et al., 2004). Equally, high bed temperatures may make supporting powders more difficult to remove following the process, so that a wide supercooling region (defining the process window) is a preferred material requirement in laser melting.

Metals and polymers are major materials used in laser melting but the available range of polymeric material types is limited. Polyamides are used extensively (e.g. Caulfield et al., 2007; Goodridge et al., 2012; Starr et al., 2011; Vasquez et al., 2011; 2013), yet other semi-crystalline polymers such as polyethylene (PE) and polypropylene (PP) only account for a small proportion of the materials used. Amorphous polymers are generally used only for building parts in AM without expectation of high durability, or in specific processes such as fused deposition modelling (FDM) (Kruth et al., 2003). Moreover, low viscosity polymers (low molecular weight (MW) grades), are usually required (Hopkinson et al., 2006) and in conventional laser melting, powder based materials are essential, so that the quality of melting also depends on the morphology of powders. Small particle size and uniform particle size distributions tend to process most effectively, offering enhanced surface finish for SLM products (Shi et al., 2004; Hopkinson et al., 2006). Therefore, innovation in process technology is required to broaden the choice of available materials, to permit the selection of new and alternative polymers to complement polyamides (including high Mw grades) and to become less dependent on the availability of powders.

An emerging laser melting technology, using a beam with Diffractive Optical Elements (DOE) designed by Laser Optical Engineering (LOE) Ltd, is used in this project. DOE, also known as holographic technology, is used to distribute the energy from the laser 
more effectively. Usually, the laser beam is focused on a small circular spot so that the distribution of the energy is usually Gaussian (Steen, 1991) in which the centre of the spot has the highest energy, reducing radially towards the edge (see Figure 1a). Thus, materials absorb energy unevenly, as the laser scans the sample to transmit according to the input parameters. It has been shown (Tyrer et al., 1996) that DOE can modify the peak energy distribution into rectangular form, thereby providing a more even energy distribution to improve process consistency and the quality of melted structures. In another application (Hou and Tyrer, 2011) HBM technology has been used to fabricate electronic circuits, using DOE elements. A curable silver epoxy-based composite was combined with a low density polyethylene (LDPE) substrate to prepare an electronic circuit. The paste was cured by lasers using both HBM and a conventional Gaussian energy laser. Results demonstrated that a high laser power or low scanning speed gave a conductive phase for the paste and that the paste prepared using holography showed higher electrical conductivity, thus demonstrating the feasibility of using holography in laser processing.

\subsection{Beam reconstruction with Holographic Optical Elements (HOE)}

The majority of laser users focus the round beam onto the work piece without any beam reconstructions or modification, i.e. a round beam with the energy cross-section governed by the laser cavity configuration. Typically, the energy cross-section is either a Gaussian profile or a high mode number thought of as a 'Top Hat'. The two kinds of beams are illustrated in Figure 1. The Gaussian beam has the majority of the energy at the centre, with a rapid decrease towards the beam edges, which will generate a non-uniform heat distribution on the work piece (Higginson et al., 2010). Moreover, since the Gaussian beam has a round shape when projected on the working plane, during a normal scan the exposure time for the central region is longer than that for the edge. This will further enhance the non-uniform distribution of the overall energy. For the 'Top Hat' beam, although its intensity distribution is nearly uniform, the round shape will also generate a non-uniform temperature distribution on the working plane.

However, polymers being fundamentally insulators require a laser beam irradiance distribution that is nominally a uniform rectilinear profile over a specified area to generate a more consistent temperature distribution if similarly traversed. Thus the laser beam needs reconstruction, which is a process of redistributing the irradiance and phase of the original beam (Freiden and Scott, 2000). The techniques using beam reflection, refraction and diffraction are developed. Simple beam stops have been used to change a laser beam shape and use it on surface coating (Steen, 1978), and a resonator has also produced a more uniform beam profile, although the actual distribution contained spikes at the corners 
(Farooq and Kar, 1999). This distribution was applied to steel during laser welding and compared with a Gaussian beam; the generated molten pool had a slightly flatter floor from the transverse direction. Laser cladding using rectangular beams has been reported (Bianco et al., 1994; Konig and Kirner, 1994), and the beam was shaped by kaleidoscope optics or by faceted mirrors. Various investigations in laser deposition and laser re-melting have been carried out in the University of Manchester (Pinkerton and Li, 2005; Safdar et al., 2007) using different beam shapes including uniform circle, rectangle and diamond. The beam reconstruction was achieved by a 'Gaussian beam array' and therefore beam intensity distribution is always uniform and only the beam shape can be reconstructed.

Using the coherent and monochromatic properties of the laser a diffractive method of beam intensity redistribution is possible. This technique is known as Holographic Optical Elements (HOE) and it works by diffraction rather than refraction/reflection. The HOE is a kinoform with a computer generated pattern on it. It is a phase only element, which will impose phase change (form 0 to $2 \pi$ ) on the illuminating beam. Figure 2 ( $a \& b$ ) shows the surface profile of a HOE, which consists of a 2D array of pixels and each assigned a different phase level. Each pixel can be thought as a point source of a spherical wave-front, emitting with controlled phase retardation. Those diffracted wave-fronts interfere in the reconstruction plane to produce the required energy profile, as illustrated in Figure 2 (c \& d).

A general process for generating a HOE has been proposed (Noden, 2000). Its surface array is firstly calculated using error reduction Iterative Fourier Transform Algorithm (IFTA) based on both the original and reconstructing beam. Then a photolithographic technique is applied in the manufacturing step. The mask is prepared by printing the generated pattern onto a photographic film, and then a silicon substrate is spun with photoresist to a controlled depth (half of wavelength of the illuminating beam). This system is exposed to UV light through the attenuating mask and the depth of the cured resist is determined by the amount of received UV light. Finally, a metallic coating with 3 layers (aluminum, copper and gold) is developed on the resist to provide a highly reflective surface.

Ekberg et al (Ekberg et al., 1991) applied the HOE on the Nd:YAG laser and successfully drilled an array of holes on a stainless steel sheet. A series of laser steel welding tests using Gaussian and several HOE reconstructed beams has also been reported (Kell et al., 2007; 2012). The authors investigated the influence of the beam shape in the weld pool shape and microstructures and found that the grain orientation can be controlled by providing different beam profiles, since the growth of grains is mainly determined by temperature gradient. By using $\mathrm{HOE}$, a user defined temperature profile on the work-piece can be generated. The thermal profile of Gaussian and HOE reconstructed beams (including 
square uniform beam and 'Rugby Post' beam with high energy intensity at the edges) has been compared during laser metal deposition and it is stated that the different temperature profile generates a driven force in the molten pool to control the material flow (Gibson et al., 2009; Higginson et al., 2010). However, all HOE tests were reported in metal processing and no applications were found in other laser processing fields such as polymer additive manufacturing.

Therefore the aim of this research is to analyse a range of thermal and physical characteristics for polymers, using polypropylene (PP) grades of variable molecular weight, to develop a more in-depth understanding of material properties towards their selection for laser melting processes using HOE. Also, the study is concluded by investigating the potential use of diffractive optical elements and holographic beam manipulation in laser melting using extruded tape samples from these material variants; a series of laser melting investigations is reported to examine the outcomes in a practical context.

\section{Experimental Methods: Materials Characterisation and Melting}

\subsection{Materials and Sample Preparation}

Polypropylene (PP) materials varying in molecular weight (MW), were selected by the respective melt flow rate (MFR) data; see Table 1. PP-A was initially in powder form (pseudo-spherical particles, mid particle size $37 \mu \mathrm{m}$ and range 5-90 $\mu \mathrm{m}$ ) and as part of the study, the other grades were mechanically ground to fine powders using a cryogenic grinding process at Queen's University, Belfast. Laser melting of PP-B and PP-C was conducted on extruded film / 'tape' materials prepared using a Betol BK32 extruder with a rectangular sheet die (200 x $1 \mathrm{~mm}$ sheet width / nominal thickness). An extensional stress induced by a haul-off device was used to achieve and control film thickness in the PP melts, by matching the drawdown ratio to the required tape thickness. The melt temperature was $180^{\circ} \mathrm{C}$ and the temperature of the cooling rolls was $60^{\circ} \mathrm{C}$; other extrusion conditions are shown in Table 2, including the approximate thickness of tapes. Different extrusion conditions were required (grades B and C) due to the variations in MW (hence melt viscosity) of the respective materials.

\subsection{Characterisation - Thermal Analysis}

Heat flow during thermal transitions such as melting and crystallisation temperatures is measured by differential scanning calorimetry (DSC). These transitions in polymers are fundamentally important in laser melting processes because the precise choice of process temperature controls the melting and solidification phase changes and also influences any 
chemical or atmospheric decomposition. TA Instruments 2010 DSC was used, with PP samples heated from ambient temperature to $200^{\circ} \mathrm{C}$ at $10^{\circ} \mathrm{C} \mathrm{min}{ }^{-1}$, then cooled to ambient temperature at the same rate, under a nitrogen gas flow $\left(50 \mathrm{~cm}^{3} \mathrm{~min}^{-1}\right)$. DSC curves were analysed using 'TA Universal Analysis' software, to observe the phase changes in the samples.

Oxidative induction time (OIT) of the samples was investigated using the same instrument (e.g. Schmid and Affolter, 2003), following DIN EN 728. Samples were heated at $20{ }^{\circ} \mathrm{C} \mathrm{min}-1$ under nitrogen, up to $240{ }^{\circ} \mathrm{C}$. The nitrogen then was replaced by an oxygen supply and the sample was held isothermally until an exothermic signal was detected, indicating the OIT under controlled conditions. Thermo-oxidative degradation of materials such as polyolefins is determined by thermogravimetric analysis (TGA): weight loss is measured as a function of temperature, during a controlled heating process, under a chosen gaseous environment. In these investigations, TGA was carried out (TA Instruments SDT 2960 TGA) at $10{ }^{\circ} \mathrm{C} \mathrm{min}{ }^{-1}$ for all PP samples in an oxygen atmosphere. Raw data can be transposed into 'derivative' data to show weight loss rate 'peaks' more clearly.

\subsection{Observation of Melting and Shear Flow}

Hot stage microscopy (HSM), often used with plane polarised light, allows structural transformations in polymers to be observed as a function of temperature. Crystalline structures are birefringent and optical images illustrate the progression of melting, as structural order is destroyed; images can be captured as stills or by video, to record the events during a phase transition. In addition, HSM also provides an excellent visual technique to record particle coalescence of powders, during melting. Powder samples from PP materials $(A-C)$ were prepared using a glass slide and coverslip; the slides were inserted into a Mettler Toledo FP82HT hot stage with FP90 central processor, which controls the $\mathrm{HSM}$ programme. Powder samples were heated from room temperature to $190^{\circ} \mathrm{C}$ at $10^{\circ} \mathrm{C}$ $\min ^{-1}$ heating rate. An optical trinocular compound microscope (Reichert Biovar) was used with the hot stage system, using a WK x15 camera eyepiece and $\times 10$ objective lens magnification; the camera is controlled by 'Scopeimage DynamicPro' software, to capture the images of the samples throughout melting.

The melt-state shear flow behaviour of materials under low deformation rates was analysed using rotational rheometry. An advanced rheometric expansion system (ARES, TA Instruments) rheometer was used at $200^{\circ} \mathrm{C}$, in steady-state parallel plate mode, using disc shaped samples of $25 \mathrm{~mm}$ diameter and $1 \mathrm{~mm}$ thickness. These were obtained using hot compression pressing at $200^{\circ} \mathrm{C}$, using a progressively increased pressure profile (between 1 and 20 tonnes) to track the melting process, so that void-free samples were obtained. $A$ 
higher compression moulding temperature $\left(220^{\circ} \mathrm{C}\right)$ was required for PP-C, due to its high melt viscosity. Rheometer output data was analysed using 'TA Orchestrator' software.

\subsection{Laser Melting using DOE / HBM}

Tape and powder materials were each melted using a custom-designed Class 4 System 1 laser machine (maximum output power $1.2 \mathrm{~kW}$ Coherent S48), with a 4-ramp Gaussian Diffractive Optical Element (DOE) laser beam. The wavelength of the $\mathrm{CO}_{2}$ laser is $10.6 \mu \mathrm{m}$, with a pulse length $0.01 \mathrm{~ms}-\mathrm{CW}$. A power meter (Coherent Labmax Model 204) was used to control the laser power. The structure of the melted part was designed by Alphacam CAD software. During the melting process, the laser is in a fixed position; the material bed moves under the laser as programmed, to selectively emit energy which is absorbed by the powder I tape materials. Bed velocity is one of the primary machine variables, relevant to these investigations.

Extruded tape materials were melted by this technique in order to prepare layered 'wall' samples (layers in the $x-y$ plane, stacked in the z-dimension), each of which contained 6 layers of tapes, which were progressively melted to each other. The melted cross-sectional area of the tape was restricted to a $35 \mathrm{~mm} \times 10 \mathrm{~mm}$ window (length \& width dimensions), within the overall length of the 'walls' (around 120mm). In this study, different thicknesses of the tapes $(20 \& 40 \mu \mathrm{m})$ were used to prepare the melted samples, using 6 initial layers, in each case. The multi-trace scan spacing was $0.2 \mathrm{~mm}$, achieved using programmed movement of the bed, relative to the laser energy source. Table 3 summarises all relevant process variables.

\section{Thermal and Physical Properties of PP - Effects of Molecular Weight}

In this section, practical data are presented to analyse a range of thermal and other physical properties of the PP materials, noting effects due to changes in MW, which will underpin their behaviour in laser melting.

\subsection{DSC and Supercooling}

Typical output data for PP from DSC analyses are shown in Figures 3-5, with quantitative data summarised in Table 4. Crystallinity data relating to endothermic melting and cooling (at $10{ }^{\circ} \mathrm{C} \mathrm{min}^{-1}$ ) have been calculated using a theoretical value of $209 \mathrm{~J} \mathrm{~g}^{-1}$ for $100 \%$ crystalline PP (Kong and Hay, 2002; Belofsky, 1995). Conventional endothermic responses were observed in all samples and melting point data confirmed the PP grades as homopolymers. Melt enthalpy and crystallinity data reflect the previous thermal history during polymer manufacture (compounding / powder processing), which is unknown. On cooling however, 
some distinctions are evident, since PP grade-C (high-MW) has a significantly higher crystallisation temperature, resulting in increased crystallinity. In many commercial PP materials, increased crystallisation kinetics in fabricated parts is often observed for low-MW polymers. The crystallisation temperature of PP increases as the molecular weight increases at relatively low MW $\left(<20,000 \mathrm{~g} \mathrm{~mol}^{-1}\right)$ but when the MW increases, the main factor which influences the crystallisation temperature is isotacticity (Billingham, 1989). However, the observed data suggest that in this case, PP-C may contain external nucleating agents, resulting in earlier onset and an increased rate of crystallisation. In many commercial processes (injection moulding, also extrusion blow moulding - a target application area for this grade) this would be an advantage but for laser melting, earlier onset of crystallisation on cooling will reduce the span of the supercooling range.

In $\mathrm{AM}$, the ideal supercooling region starts from the temperature where the melting of low-perfection crystallites begins (on heating), to the temperature at which crystallisation initiates within the process cooling regime (Vasquez et al., 2011). It is important to ensure that semi-crystalline polymers are cooled slowly within this region, otherwise non-uniform shrinkage occurs resulting in poor dimensional stability of the melted construction. For semicrystalline polymers in conventional laser melting, achieving a wide supercooling region is critical to the success of the process and influences the choice of process parameters on melting (laser power, scan speed) and on subsequent consolidation (powder bed temperature) and therefore the optimum choice of polymers and synthesis route for this process, polyamide 12 (PA12) being an excellent example. Supercooling data for the PP grades studied can be estimated from the DSC data in Table 4 and are typically in the range 30-38 ${ }^{\circ} \mathrm{C}$ for PP, very similar to supercooling ranges for PA12 and thermoplastic polyurethane (TPU), as detailed elsewhere (Vasquez et al, 2014). The supercooling range of polymers can potentially be further increased by molecular architecture and by use of copolymers.

\subsection{TGA and Stable Melting Region}

Dynamic thermogravimetric data are shown in Figures 6-8, both directly and as derivative data, which identifies the position of maximum decomposition rate more clearly. The respective temperatures corresponding to $1 \%$ weight loss can be taken as the practical onset of degradation; these values are 214,230 and $243^{\circ} \mathrm{C}$ for PP grades A, B and C (respectively). These data can then be used to inform process conditions in laser melting and thereby contribute to the definition of a stable melting region, a concept that has been reported previously for conventional laser melting processes (Vasquez et al., 2011; 2013). 
During laser melting, the polymeric materials absorb energy from the laser, the temperature is increased dramatically and powder materials coalesce with adjacent particles above the melting temperature range. High surface free energy and low viscosity is required to accelerate the particle coalescence and melting kinetics (Haworth et al., 2013). In the HBM process, tape materials are melted by a similar mechanism and individual layers adhere to each other at high temperature to prepare 'walls'. However, materials will start to undergo chemical decomposition at temperatures which permit degradation (typically oxidation for polyolefins) within the timescale of the process. Thus, a suitable temperature range should be determined during the melting process, in order to obtain an effective laser melted part.

TGA and DSC results can be superposed to construct a 'stable sintering region' (SSR), defining an available process window between the endothermic melting point and the point where degradation initiates (Vasquez et al, 2011; 2013; Haworth et al, 2013). When laser melting is conducted in this region, the materials will be fully melted without significant risk of decomposition (see Figures 9-11 for polypropylene, PP). Table 5 shows the predicted SSR data for each grade of PP; the lower temperature limit is above the completion of endothermic melting (when the heat flow becomes stable) and the upper temperature limit is defined by TGA data. It should be noted that changes in some test conditions will define these parameters and the SSR more precisely. For example, the heating rate in DSC will influence endothermic melting to a limited extent, whilst the TGA data are also influenced by heating rate and if conducted under an 'aggressive' oxygen atmosphere, degradation will be accelerated relative to air or inert gas atmospheres. Thus, in practice, the SSR is wider than the predicted regions shown here since the upper temperature limit is higher than values shown in Table 5. Clearly the test conditions can be carefully matched to the process which is being simulated.

\subsection{Oxidation Induction Time (OIT)}

Further information on thermo-oxidative decomposition of polyolefins may be obtained using OIT (Schmid and Affolter, 2003). Table 6 shows the oxidative induction times for the three PP samples at $240^{\circ} \mathrm{C}$ : OIT values are very similar, indicating the stability in an oxygen-rich environment at the chosen temperature, which (in this case) is above the recommended SSR. PP chains include tertiary hydrogen atoms and oxidative degradation of PP is a free radical reaction that effectively reduces molar mass (Russell and Pascale, 1963; Billingham, 1989; Livanova et al., 1997). However, since all commercial PP grades contain antioxidanttype stabilisers, the OIT data are strongly dependent on the type, amount and the properties of the additives, which is proprietary information. 
During melting, the material is subjected to a high energy laser, which potentially might induce very high surface temperature. Thus, the OIT results may be considered to represent an indication of safe process residence time at the chosen temperature, for the materials, so that polymers should be melted within the OIT at a specific temperature, otherwise, the material will start to degrade. According to the results for PP presented here, the chosen OIT test temperature $\left(240{ }^{\circ} \mathrm{C}\right)$ was higher than the upper temperature SSR limits of three PP grades so that the safe processing time in AM builds will be extended further if laser melting is conducted within the SSR. Predictions of chemical kinetics can be made using Arrhenius-type relationships to explore process windows (Laidler, 1984). In addition, since the OIT measurement was conducted in an oxygen atmosphere, whereas laser melting is usually conducted in air or in an inert gas atmosphere, the maximum process time will be extended if both the gas atmosphere and lower temperatures are considered. In practice, the process residence time in the HBM laser melting process depends on the velocity of the material bed, as it moves relative to the beam. Thus, the limiting process parameters are effectively the lower-bound bed velocity and the beam diameter.

\subsection{Shear viscosity data}

Previous studies of laser melting have identified the importance of the melt-state viscosity, especially at low strain rate, as being critically important to describe or predict melting kinetics (Hornsby and Maxwell, 1992; Haworth et al., 2013). Shear viscosity of high polymers is well known to be sensitive to molecular weight, so that experiments were carried out to determine the comparative shear flow behaviour of the three PP grades, using steady-state rotational rheometry.

Figure 12 shows the shear viscosity obtained from rotational rheometry at $200^{\circ} \mathrm{C}, \mathrm{a}$ typical process temperature within the stable melting region. By convention, the data are represented in bi-logarithmic format, showing shear viscosity decreasing by orders of magnitude as shear rate increases. There are many model representations for this type of pseudoplastic flow behaviour, from the simple power law in the linear (high strain rate) region (equation 2) to other, more accurate relationships such as Carreau and Cross-WLF models, which account for the tendency towards Newtonian behaviour (non-linear strain rate dependence) and also temperature sensitivity. The power law is strictly limited to linear

regions of shear flow curves and is given by: $\quad \eta=k(\dot{\gamma})^{n-1}$

$\eta$ is shear viscosity, $\dot{\gamma}$ is shear rate and $\mathrm{k} \& \mathrm{n}$ are the power law constants ( $\mathrm{n}$ represents the power law index, an indication of the degree of pseudoplasticity). 
At any given temperature, the 3-parameter Cross model (equation 3) also relates shear viscosity to shear strain rate in both linear and non-linear regions and includes 'zeroshear viscosity' $\left(\eta_{0}\right)$, which can be determined experimentally using steady-state viscous flow data of the type shown in Figure 12:

$$
\eta=\frac{\eta_{0}}{1+\left(\frac{\eta_{0} \dot{\gamma}}{\tau^{*}}\right)^{1-n}}
$$

$\tau^{*}$ indicates the stress at the transition to shear thinning (pseudoplastic) behaviour

Zero shear viscosity is observed by extrapolating shear viscosity at very low shear rates; in this study, the zero shear viscosity was estimated at $0.1 \mathrm{~s}^{-1}$ shear rate. PP-A shows typical behaviour of low-MW materials with near Newtonian behaviour when the shear rate is $1 \mathrm{~s}^{-1}$, approx. Table 7 summarises the power law constants (from the linear region of the flow curves) and the Cross model constants to show molecular weight sensitivity, for PP. The dependence of shear viscosity on shear deformation rate is therefore much more apparent at low strain rates, and since this is the region in which melting is carried out, these relationships carry enormous significance when selecting materials for AM processes. In addition, molecular weight has a profound influence on viscosity of polymers and the relationship is given as $\eta_{0}=C(M w)^{a} \begin{aligned} & \text { zero shear } \\ & \text { follows (Lobo }\end{aligned}$ and Bonilla, 2003):

$\eta_{0}$ is zero shear viscosity, $C$ and a are constants and $\mathrm{Mw}$ is weight average molecular weight. Usually, the value of a is around 3.4-3.6 for high molar mass, commercial polymers. Using this approach, polymeric materials can be synthesised and selected to offer the required viscosity characteristics for laser melting, taking account of deformation rate and temperature. Molecular weight sensitivity during the melting process is examined in the next section.

\subsection{Hot-stage microscopy of PP powders}

Hot stage microscopy is used for observing temperature dependent structure transformations in polymers and is effective when semi-crystalline materials undergo melting, especially in powder form when the magnification can be adjusted appropriately, to observe melting behaviour(Vasquez et al., 2013). Figures 13-15 show 'still' images taken from the video footage during dynamic heating. In particular, Figure 13 (PP-A, low MW) shows these images over a larger temperature range. It can be concluded that initial particle coalescence ('bridging') at the onset of melting takes place at temperatures within the melting endothermic range for $\mathrm{PP}$, but below the peak melting temperature of approx. $168^{\circ} \mathrm{C}$ (see 
Figures 3-5). Melting then becomes progressive and the extent of melting increases with temperature, above the melting point, as viscosity reduces. Hence, if the processing is conducted at increased temperatures, particles coalesce more quickly but to an extent which also depends more critically upon molecular weight.

Figure 13(A) shows the original particle morphology before melting; as temperature increases the particles expand, undergo a progressive phase change, more contact points are formed (Figure 13B), melting initiates from the centre of contact points and the neck grows radially as the powder particles coalesce (Rhodes, 1981). From the micrographs in Figures 13-15, the temperatures observed by HSM at the onset of necking are (respectively): $160.5,160.8$ and $163.6^{\circ} \mathrm{C}$, for PP grades A-C, confirming that the onset of the melting process, for a given polymer type, is dependent on the position of the melting endotherm and is largely independent of molecular weight. In the HSM images, structural order is observed in the solid, semi-crystalline particles, but is gradually eliminated during melting when the material resides in its amorphous melt-state and becomes transparent to polarised light; Figure 13 (images A-F) is the best illustrative example.

According to the Frenkel sintering model (Muller et al., 2008) (equation 5), the progressive rate of melting (hence process sintering time) is influenced by zero shear viscosity, which is a function of molecular weight (Figure 12) and temperature (Haworth et al., 2013), hence:

$$
\frac{x}{r}=\left(\frac{3 \sigma t}{2 r \eta_{0}(T, M w)}\right)^{1 / 2}
$$

$x$ represents the degree of particle coalescence, $r$ is the original radius of spherical particles, $\sigma$ is surface free energy and $t$ is melting time. However, in this study, melting times cannot be predicted directly since the HSM experiments were not conducted under isothermal conditions. In dynamic mode, the temperature increases at a controlled rate, so that viscosity is not constant. This predictive model is only valid for the onset and early progression of melting and for wholly viscous flows at low strain rates, and assumes that particle radius and the viscosity parameter are considered constant. Whilst there is some temperature sensitivity of viscosity, it is unlikely that $\sigma$ will be significantly different for the three grades of the same generic polymer type without chemical modification, so that zero shear viscosity is the dominant material property influencing melting rate.

Given the zero shear viscosity for three samples (Figure 12), and assuming a constant value for surface free energy for isotactic PP of $30.1 \mathrm{~mJ} \mathrm{~m}^{-2}{ }^{[1]}$, the relative progression of the early stages of melting ( $x / r$ versus time) at $200^{\circ} \mathrm{C}$, as a function of $\mathrm{MW}$, can be approximated using the Frenkel model. Figure 16 verifies the importance of selecting 
polymer grades with optimum molecular weight; the predicted rate of particle coalescence is enhanced considerably when the viscosity decreases, consistent with earlier research on PA12 (Haworth et al., 2013).

It should also be noted that in our experiments, the average powder particle size (hence radius parameter, $r$ ) of PP-A was significantly lower than for the mechanically ground powders (PP-B and PP-C); the respective average particle sizes were $37 \mu \mathrm{m}(\mathrm{A})$ and around $90 \mu \mathrm{m}$ (ground powders $\mathrm{B}$ and $\mathrm{C}$ ). Clearly this difference will influence melting rate predictions. The hot stage microscopy tool provides a stable thermal condition, since the heating source is uniform, with a large area. In any laser melting process, the laser is focused upon a specific part of the powder (the area of laser is limited to the spot footprint) and energy is transferred at a rate depending on the scan speed / bed velocity. This leads to the existence of thermal gradients within the polymer feedstock, dependence on thermal diffusivity within the bulk powder, thereby adding to the complexity of process simulation. Therefore, the results from HSM are useful to identify the progression of melting and specification of the relevant temperature range over which this takes place.

\section{$4 \quad$ Laser Melting Process (HBM)}

A short series of experiments was carried out to verify the effects of molecular weight, for PP grades $\mathrm{A}-\mathrm{C}$, on the melting characteristics to prepare artefacts using the HBM process. For melting experiments carried out using thin, extruded tape specimens (as opposed to powder), peel tests were conducted in order to test the degree of interlayer adhesion within the 'walls'. The force required to separate adjacent layers was measured using $180^{\circ}$ deformation at a constant rate of $100 \mathrm{~mm} \mathrm{~min}^{-1}$ on a Lloyd LR50k testing machine. In Table 8, ' $X$ ' denotes that a degree of delamination occurred during testing, so that all other samples were sintered successfully, demonstrating that high molar mass polymers are potentially able to be sintered by this process. Quantitative data are available for the delaminated samples, but these show little difference between PP-B and PP-C and are not reported here. Figure 17 shows an example of a fully sintered sample: the sintered area is in the centre of the sample, whilst towards the edges, each layer was damaged without significant bonding (i.e. outside the sintered area). Bed velocity and initial layer thickness are each shown to be important variables (Table 8). The relative scan speed is effectively controlled by the bed velocity, which has an optimum range of 10 to $15 \mathrm{~mm} \mathrm{~min}^{-1}$ at $7.5 \mathrm{~W}$ laser power (for both PP-B and PP-C). The beam is incident on the samples for a longer time at low bed speed, allowing greater energy transfer. The thickness of the extruded PP layers also influences the absorption of laser energy. Clearly, thicker layers need more power to be sintered, for 
components with a given number of layers in the build. In situations where the component thickness is held constant, heat transmission across thin layers will be less dependent upon internal conduction, but will be retarded by the existence of air gaps between the layers. In our experiments, delamination occurred in samples prepared with high bed velocity and increased layer thickness. Other process parameters are available for further investigation, including laser power and spot diameter. Parameter variations would be required to define an acceptable process window, within the overall stable melting region defined earlier.

Another indication of the goodness of melting is a simple measurement of postprocess sintered part thickness, relative to the original number and of extruded tape layers. The thickness high-Mw PP-C (20 $\left.\mu \mathrm{m}, 10 \mathrm{~mm} \mathrm{~min}^{-1}\right)$ was $126 \mu \mathrm{m}$, almost exactly equal to the theoretical value, indicating full melting. In contrast, PP-C $\left(20 \mu \mathrm{m}\right.$ and $\left.20 \mathrm{~mm} \mathrm{~min}^{-1}\right)$ had a measured thickness of $349 \mu \mathrm{m}$, demonstrating incomplete melting and partially-separated layers. These results are verified by the optical images of component cross-sections in Figure 18.

Overall, the initial results demonstrate that PP-B and PP-C (both of which are relatively high MW grades of $\mathrm{PP}$ ) have potential to be laser sintered by this method from extruded tape, rather than from powder form. In consequence there is also potential to increase the range of polymer types which could be used in the process (including variations in molecular weight), incorporation of reinforcing additives (glass or carbon fibres), toughening agents (elastomers) or complex pigmentation systems. These would be prepared into thin tape / film using conventional melt-state extrusion processes (avoiding the requirement to use powders), in which excellent process control is available to manufacture films with precise levels of thickness. The versatility of polymer-based materials can also be used to advantage, in order to tailor specific grades to meet the requirements of the laser melting process (additional antioxidant to improve stability and to expand the stable melting region) or to meet specific product and mechanical properties criteria, which might include enhanced surface finish, or increased stiffness (using reinforced composites) and durability (elastomer-modified grades).

\section{$5 \quad$ Summary and Conclusions}

Three commercial grades of PP were selected for the studies of molecular weight, hence different viscosities during the melting process. Crystalline melting points were similar, although one grade had an earlier onset of crystallisation, resulting in a reduced supercooling region; this is attributed to an external nucleating species, rather than effects 
due to molar mass. TGA results were analysed by a '1\% weight loss' parameter, considered to represent the start of significant thermo-oxidative degradation of PP during dynamic heating. The 'stable melting region' for each material was then obtained by combining the DSC and TGA data and this varies between temperatures of around $178-180^{\circ} \mathrm{C}$ (end of the thermodynamic melting endotherm) to temperatures up to $240^{\circ} \mathrm{C}$, defining the thermal process window available for melt-state laser melting. OIT analysis is used to obtain quantitative data relating to degradation kinetics of specific chemical decomposition processes, as a function of melting temperature; for $\mathrm{PP}$, additional resistance to oxidation can be achieved by re-formulating with additional or modified antioxidant stabilisers.

Hot stage microscopy simulates the necking process which initiates melting and identifies the temperature at which this process starts. For semi-crystalline PP exhibiting a wide melting range, the necking temperatures occur when the less perfect crystallites start to melt and these were around $160^{\circ} \mathrm{C}$, except for the high-Mw grade $\left(164^{\circ} \mathrm{C}\right)$. Rotational rheometry was used to confirm the pseudoplastic shear flow behaviour of the PP materials and determines the respective zero-shear viscosity values, which vary markedly with molecular weight in the anticipated manner, ranging from $0.91 \mathrm{kPa} . \mathrm{s}$ (low-Mw PP), to 22.9 kPa.s for the high-MW grade.

Laser melting using the holographic beam manipulation (HBM) technique was carried out to manufacture samples from extruded thin tapes, thus avoiding the use of powders, which were characterised by mechanical peel testing and by optical microscopy. Some degree of success was achieved in melting parts with high molecular weight grades of PP and melting was related to the level of delamination observed. The effectiveness of melting depends on the tape thickness and the bed velocity; optimum results were obtained using low tape thickness $(20 \mu \mathrm{m})$, especially at low bed velocity $\left(10,15 \mathrm{~mm} \mathrm{~min}^{-1}\right)$ where greater heat energy is absorbed by the polymer. Components formed using tapes with higher thickness clearly require more heat energy for melting and high laser power should be provided.

Although the stable region for laser melting has been analysed for the PP materials, the relationships between the temperature and corresponding laser power should be carefully identified in future work. Other improvements to the process are possible (for example, use of a heated material bed, thus maintaining the consolidation temperature within the supercooling range) and can be introduced to match the specific thermal and viscosity characteristics of other polymer types. For powders, particle size has a major influence on the heat transfer kinetics and the quality of sintered samples, so that fine particles should be used in laser melting. It is anticipated that the results from this study 
could be transferred to other grades of PP, including blends, copolymers and elastomermodified materials and indeed to other type of semi-crystalline polymers of variable molecular weight.

\section{References}

Belofsky, H., (1995), "Plastics: product design and process engineering", Carl Hanser, Munich.

Bianco, M., Rivela, C. and Talentino, S., (1994), "On-line surface treatment feasibility of industrial components by means of $\mathrm{CO}_{2}$ power laser", Laser Materials Processing: Industrial and Microelectronics, Vol. 2207, pp.53-61.

Billingham, N.C., (1989), "Localisation of oxidation in polypropylene", Makromol. Symposia, Vol. 28, pp.145-163.

Caulfield, B., McHugh, P.E. and Lohfeld, S., (2007), "Dependence of mechanical properties of polyamide components of build parameters in the SLS process", Journal of Mat. Process.Technol., Vol. 182, pp.477-488.

Chu, C., Graf, G. and Rosen, W.D., (2008), "Design for additive manufacturing of cellular structure", Computer-aided design and applications, Vol. 5, pp.686-696.

Ekberg, M., Larsson, M., Boller, A. and Hard, S., (1991), "Nd:YAG laser machining with multilevel resist kinoform", Applied Optics, Vol. 30, pp.3604-3606.

Farooq, K. and Kar, A., (1999), "Effects of laser mode and scanning direction on melt pool shape", Journal of Applied Physics, Vol. 85, pp.6415-6420.

Freiden, M.D. and Scott, C.H., (2000), "Laser beam shaping: theory and techniques", Marcel Dekker, New York.

Gibson, M., Higginson, R.L. and Tyrer, J., (2009). "The control of grain size during welding and direct metal deposition using three dimensional time-temperature control provided by holographic beam shaping", Proc. Conf. ICALEO, Paper 1505.

Gibson, I. and Shi D., (1997), "Material properties and fabrication parameters in selective laser sintering process", Rapid Prototyping Journal, Vol.3, pp.129-136.

Goodridge, R.D., Tuck, C.J. and Hague, R.J.M., (2012), "Laser sintering of polyamides and other polymers", Progress in Materials Science, Vol. 57, pp.229-267. 
Haworth, B., Hitt, D.J., Hopkinson, N. and Vasquez, G.M., (2013), "Laser sintering process for polymers: influence of molecular weight and definition of a stable sintering region", Polymer Processing Society PPS-29 Conf., Paper S18-308, pp.1-4, Nuremberg, Germany. Haworth, B., Hitt, D.J., Hopkinson, N, and Zhong, X., (2013) "Shear viscosity measurements on polyamide-12 for laser sintering", Rapid Prototyping Journal, Vol. 19, pp.28-36.

Higginson, R.L., Gibson, M., Kell, J. and Tyrer, J., (2010). "Weld pool shaping and microstructural control using novel computer generated holographic optic laser welding of steel and stainless steel", Materials Science Forum, Vol. 638-642, pp.3673-3678.

Hopkinson, N, Hague, R.J.M, and Dickens, P.M., (2006), "Rapid manufacturing: an industrial revolution for the digital age", Wiley, New York.

Hornsby., P.R. and Maxwell, A.S., (1992), "Mechanism of sintering between polypropylene beads", J. Mat. Sci., Vol. 27, pp. 2525-2533.

Hou, S. and Tyrer, J., (2011), "Drawing electronic circuits - the production of electronic components with embedded direct written circuits using holographic beam manipulation", Proc. Conf. ICALEO, Paper \#M801.

Kell, J. (2007). PhD thesis: "Melt pool and microstructure manipulation using diffractive holographic elements in high power conduction laser welding", Loughborough University, UK.

Kell, J., Tyrer, J.R., Higginson, R.L., Jones, J.C. and Noden, S., (2012). "Laser weld pool management through diffractive holographic optics", Materials Science and Technology, Vol. 28, pp.354-362.

Kong, Y. and Hay, J.N., (2002) "Measurement of the crystallinity of polymers by DSC", Polymer, Vol.43, pp.3873-3878.

Konig, W. and Kirner, P.K., (1994), "Laser surface treatments prolong tool life", Proc. SPIE 2207, Laser Materials Processing: Industrial and Microelectronics, Vol. 2207, 44-52.

Kruth, J.P., Wang, X., Laoui, T. and Froyen, L., (2003), "Lasers and materials in selective laser sintering", Assembly Automation, Vol. 23, pp.357-371.

Laidler, K.J., (1984), "The development of the Arrhenius equation", Journal of Chemical Education, Vol. 61, pp.494-498. 
Levy, G.N, Schindel, R. and Kruth J.P., (2003), "Rapid Manufacturing and Rapid Tooling with Layer Manufacturing (LM) Technologies; State of the Art and Future Perspectives", Cirp Annals Manuf. Technol., Vol. 52, pp.589-609.

Livanova, N.M. and Zaikov, G.E., (1997), "The initiation of polypropylene oxidation", Polymer Degradation and Stability, Vol. 57, pp.1-5.

Lobo, H. and Bonilla, J.V., (2003), "Handbook of Plastics Analysis", Marcel Dekker, New York.

Lu, L. and Fu, J.Y.H., (2001), "Laser Induced Materials and Processes for Rapid Prototyping", Kluwer Press, Dordrecht.

Muller, J-D., Bousmina, M. and Maazooz, A., (2008), "2D-Sintering Kinetics of Two Model Fluids as Drops", Macromolecules, Vol. 41, pp.2096-2103.

Noden, S. (2000), Applications of Diffractive Optical Elements with High Power Lasers, PhD Thesis, Loughborough University, UK.

Pinkerton, A.J. and Li, L., (2005), An experimental and numerical study of the influence of diode laser beam shape on thin wall direct metal deposition, J. Laser Applications, Vol. 17, pp. 47-56.

Rhodes, M.J., (1981), Principles of Powder Technology, John Wiley \& Sons, New York.

Russell, C.A. and Pascale, J.V., (1963), "The early stages of isotactic polypropylene oxidation", J. Appl. Polym. Sci., Vol. 17, pp.959-969.

Safdar, S., Li, L. and Sheikh, M.A., (2007), "Numerical analysis of the effects of nonconventional laser beam geometries during laser melting of metallic materials", J. Physics \& Applied Physics, Vol. 40, 593-603.

Schmid, M. and Affolter, S., (2003), "Interlaboratory tests on polymers by differential scanning calorimetry (DSC): determination and comparison of oxidation induction time (OIT) and oxidation induction temperature (OIT*)", Polymer Testing, Vol. 22, pp.419-428.

Shi, Y., Li, Z., Sun, H., Huang, S. and Zeng, F., (2004), "Effects of the properties of the polymer materials on the quality of selective laser sintering parts", Proc. Inst. Mech. E. Part L; J. Materials: Design and Application, Vol. 218, pp.218-247.

Starr, T., Gornet, T. and Usher, J., (2011), "The effect of process conditions on mechanical properties of laser-sintered nylon", Rapid Prototyping Journal, Vol. 17, pp.418 - 423. 
Steen, W., (1978), "Surface coating using a laser", Advances in Surface Coating Technology, Vol. 13-15, pp.175-187.

Steen, W.M. (1991), Laser Materials Processing, Springer-Verlag, London.

Tyrer, J.R., Noden, C.S. and Hilton, A.P., (1996) "Diffractive optical elements for manipulation of high power $\mathrm{CO}_{2}$ laser radiation - a feasibility study", High-power Lasers: Application and Emerging Applications, Vol. 2789, pp.174-185.

Vasquez, G.M., Haworth, B. and Hopkinson, N., (2013), "Methods for quantifying the stable sintering region in laser sintered polyamide-12", Polym. Eng. Sci., Vol. 53, pp.1230-1240. Vasquez, M., Haworth, B. and Hopkinson, N., (2011), "Optimum sintering region for laser sintering nylon-12", Proc. I. Mech. Eng. Part-B - Journal of Engineering Manufacture, Vol. 225, pp.2240-2248.

Vasquez, G.M., Majewski, C.E., Haworth, B. and Hopkinson, N., (2014), "A targeted materials selection process for polymers in laser sintering", Additive Manufacturing, Vol. 1-4, pp.127-138.

Yan, X. and Gu, P, (1996), "A review of rapid prototyping technologies and systems", Computer-aided Design, Vol. 28, pp.307-318.

[I] Anon; "Solid surface energy data (SFE) for common polymers", available at: http://www.surface-tension.de/solid-surface-energy.htm/ (accessed 24 August 2016). 
Figures and Captions

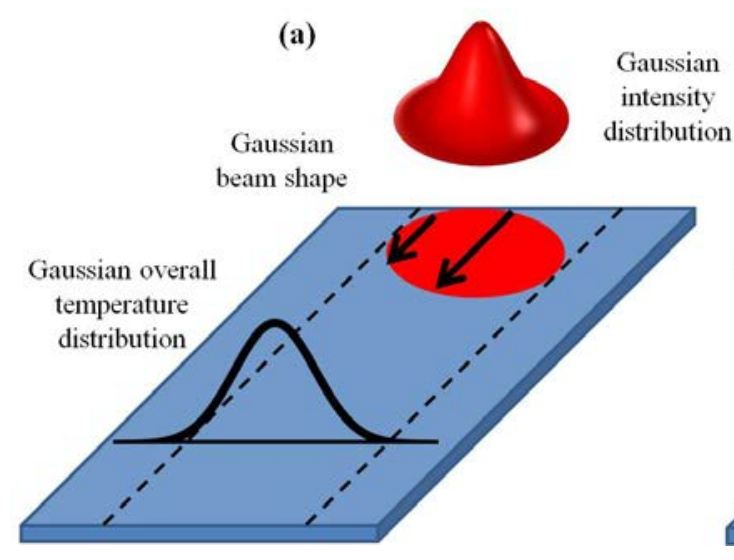

(b)

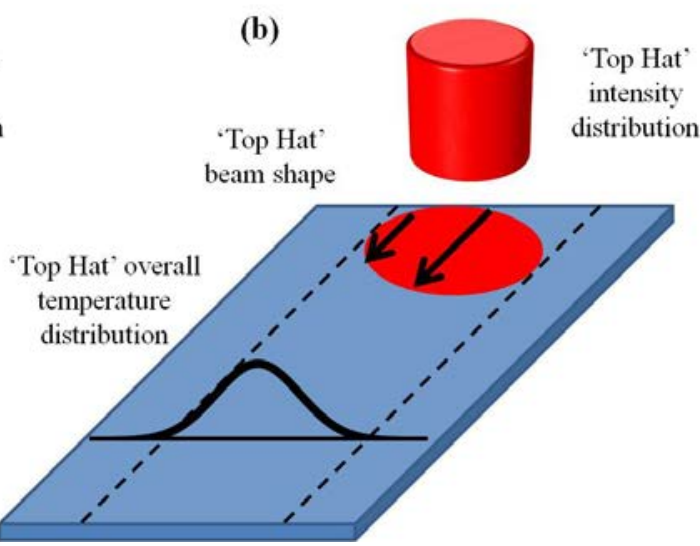

Figure 1 Non-uniform energy distribution during (a) Gaussian beam and (b) 'Top Hat' beam scan

(a) HOE surface pattern

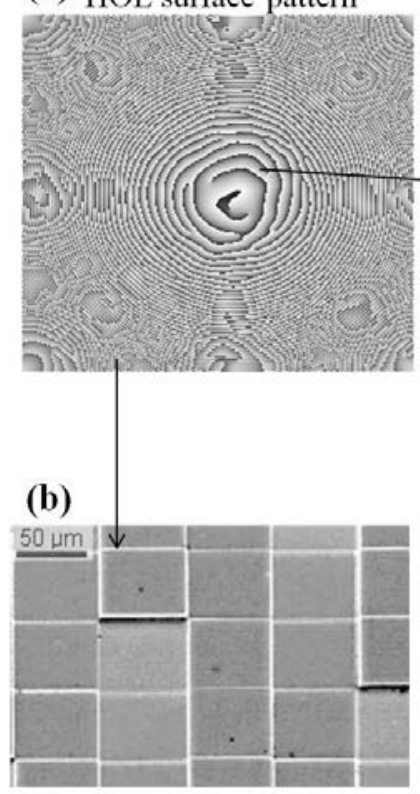

2D arrays at high magnification

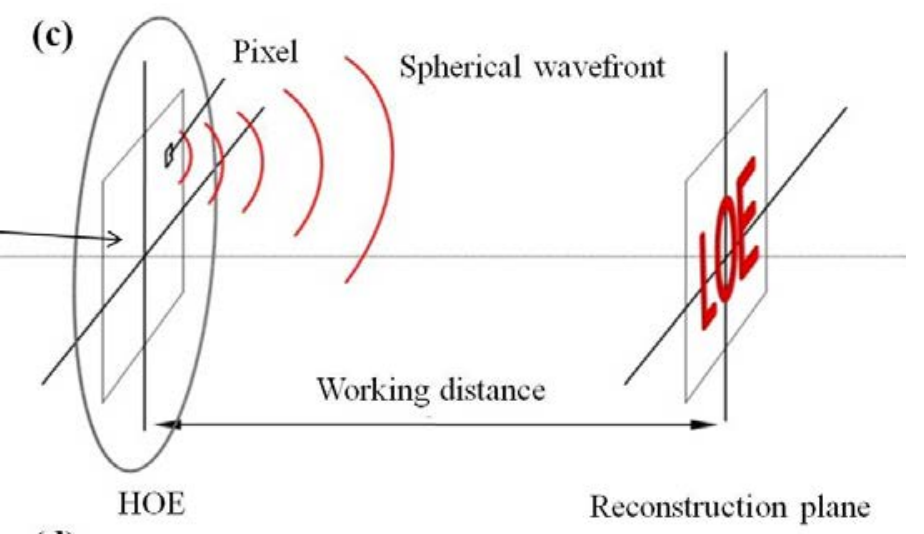

(d)

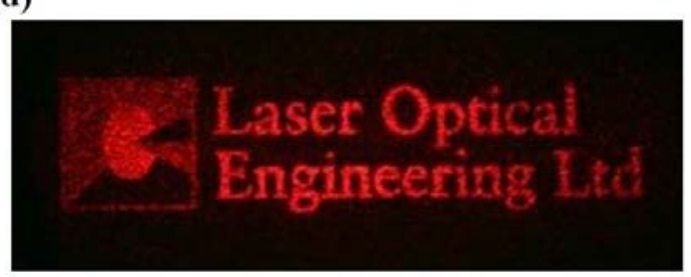

An example of reconstructed beam

Figure 2 (a) Surface pattern of HOE; (b) 2D arrays of pixels; (c) working mechanism of the HOE pixel; (d) An example of beam reconstruction 


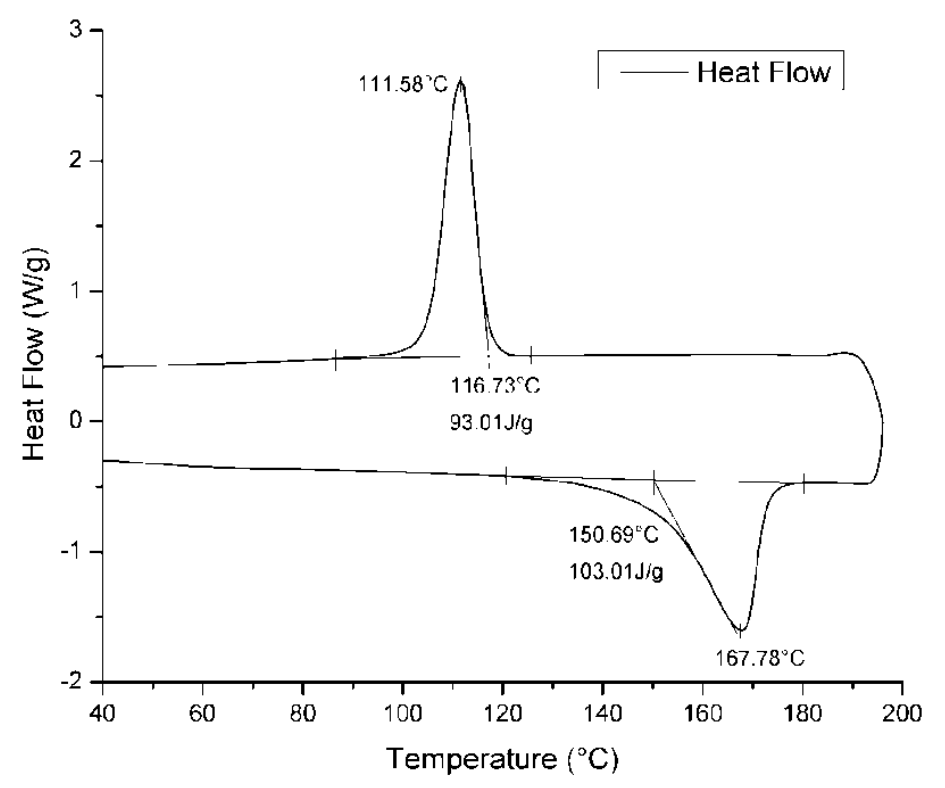

Figure 3 DSC heating / cooling curves for PP grade-A (low MW).

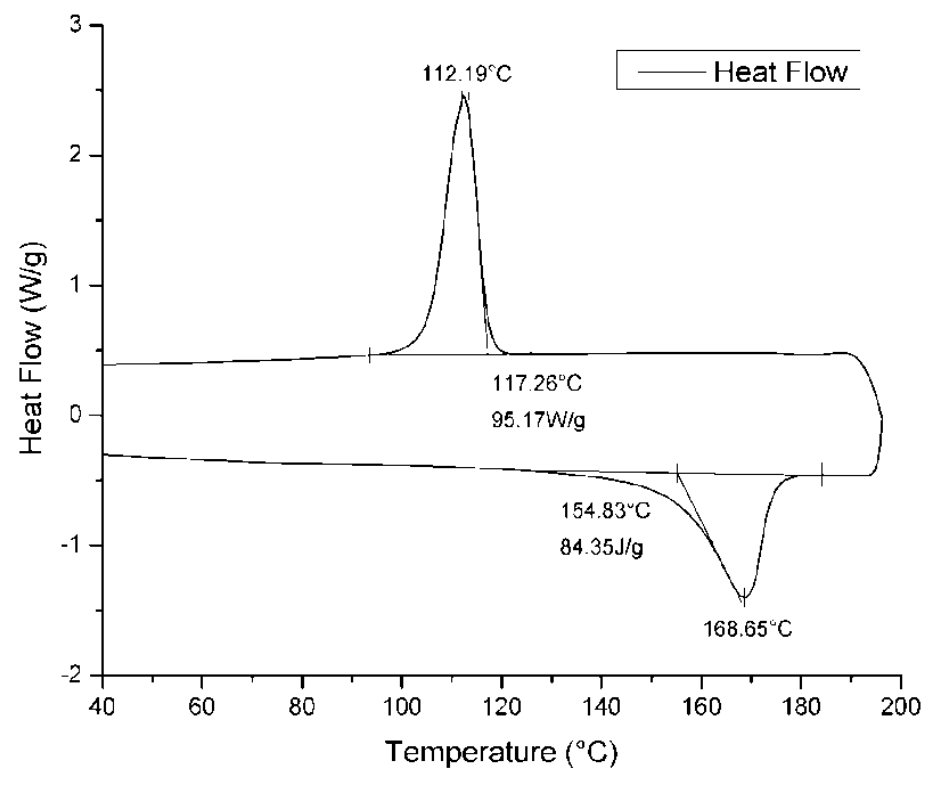

Figure 4 DSC heating / cooling curves for PP grade-B (medium MW). 


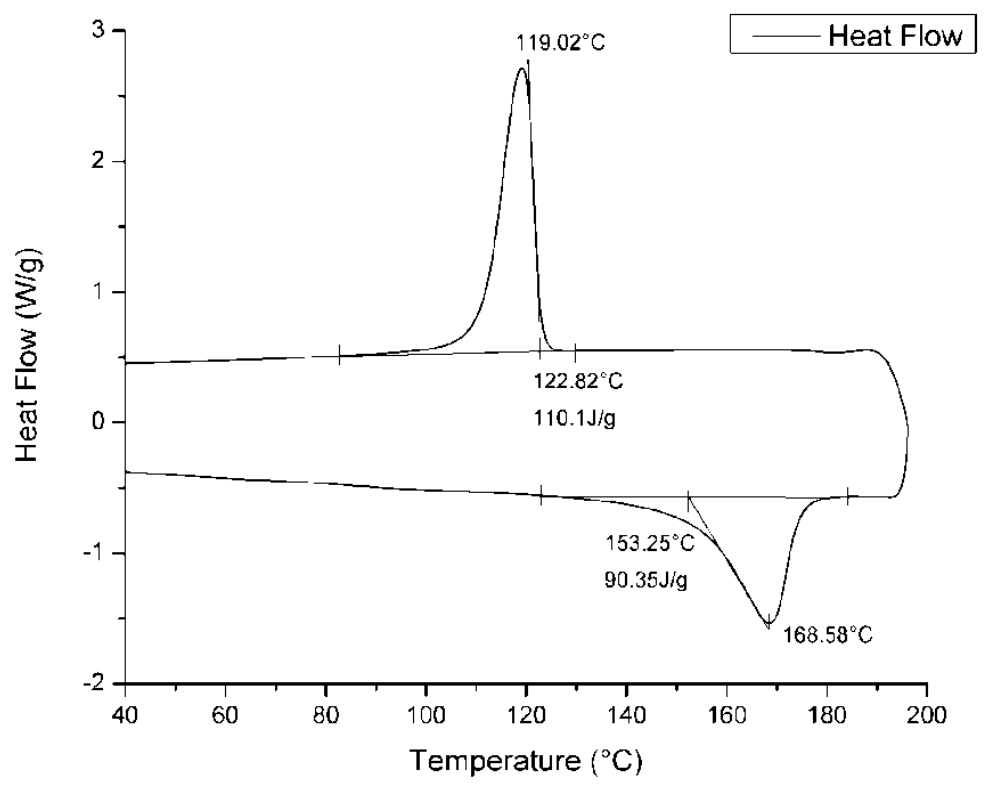

Figure 5 DSC heating / cooling curves for PP grade-C (high MW).

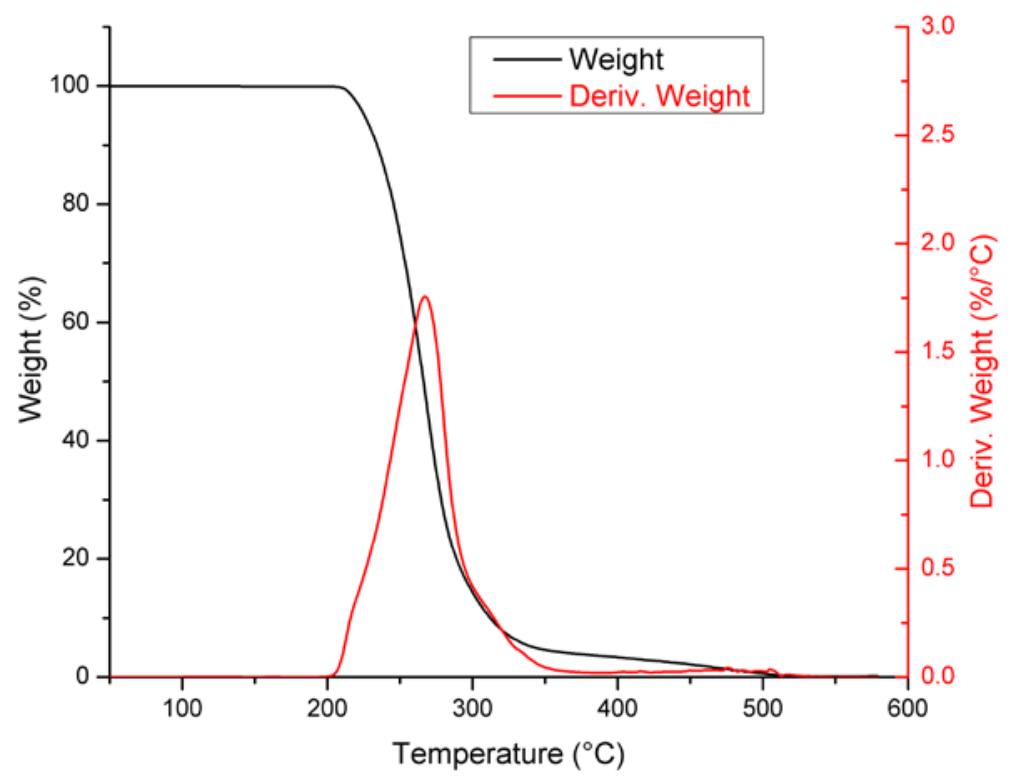

Figure 6 TGA dynamic heating / derivative data for PP grade-A (low MW). 


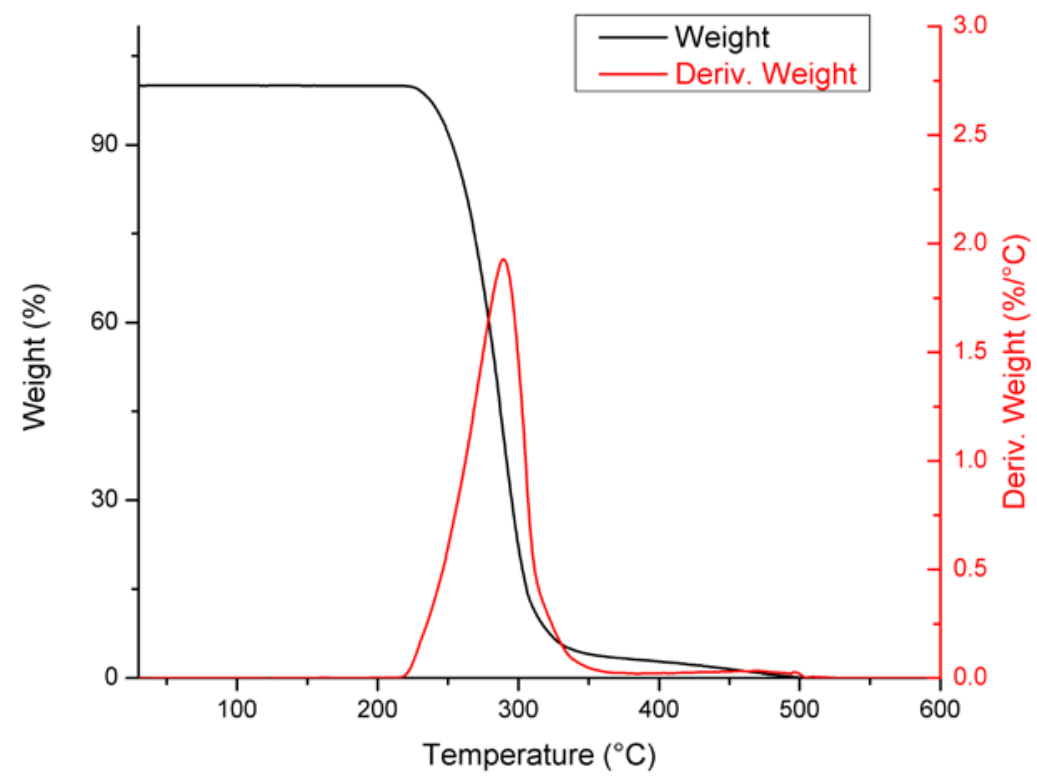

Figure 7 TGA dynamic heating / derivative data for PP grade-B (medium MW).

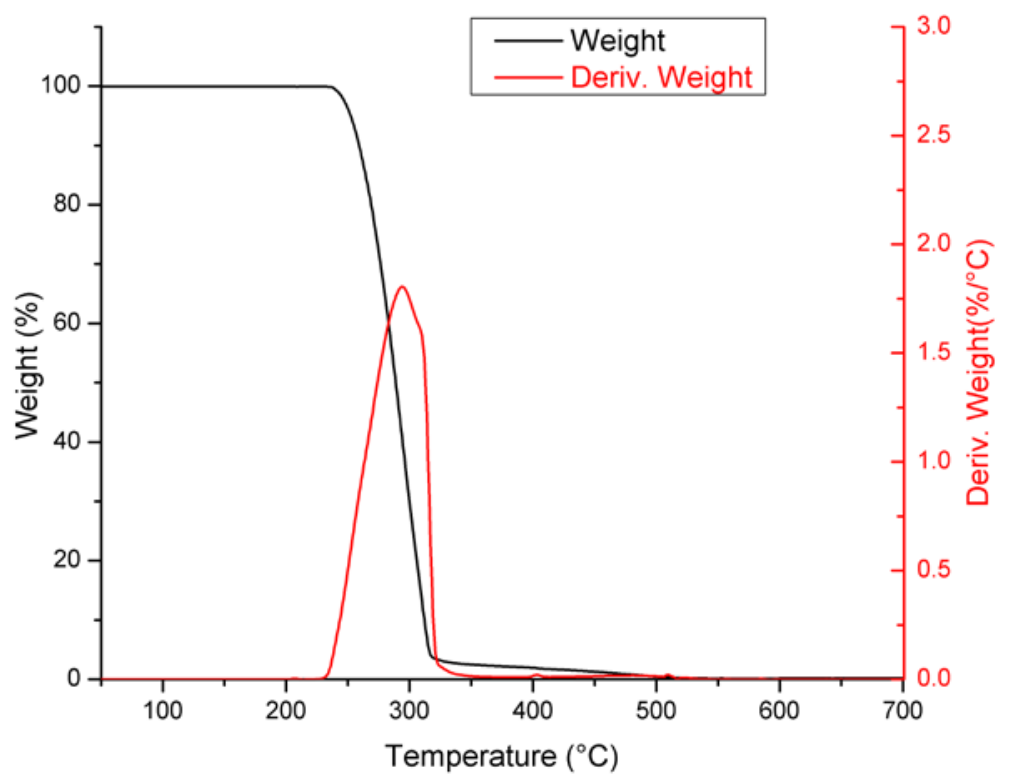

Figure 8 TGA dynamic heating / derivative data for PP grade-C (high MW). 


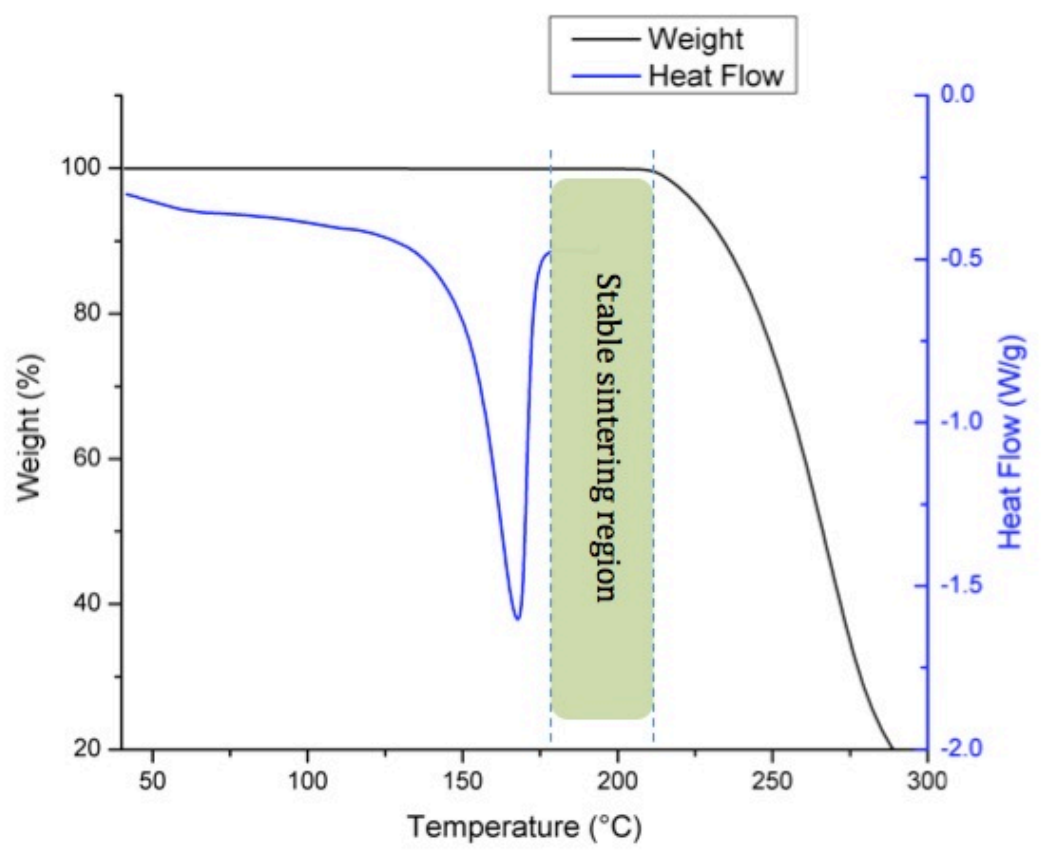

Figure 9 Stable melting region (DSC I TGA) for PP grade-A (low MW).

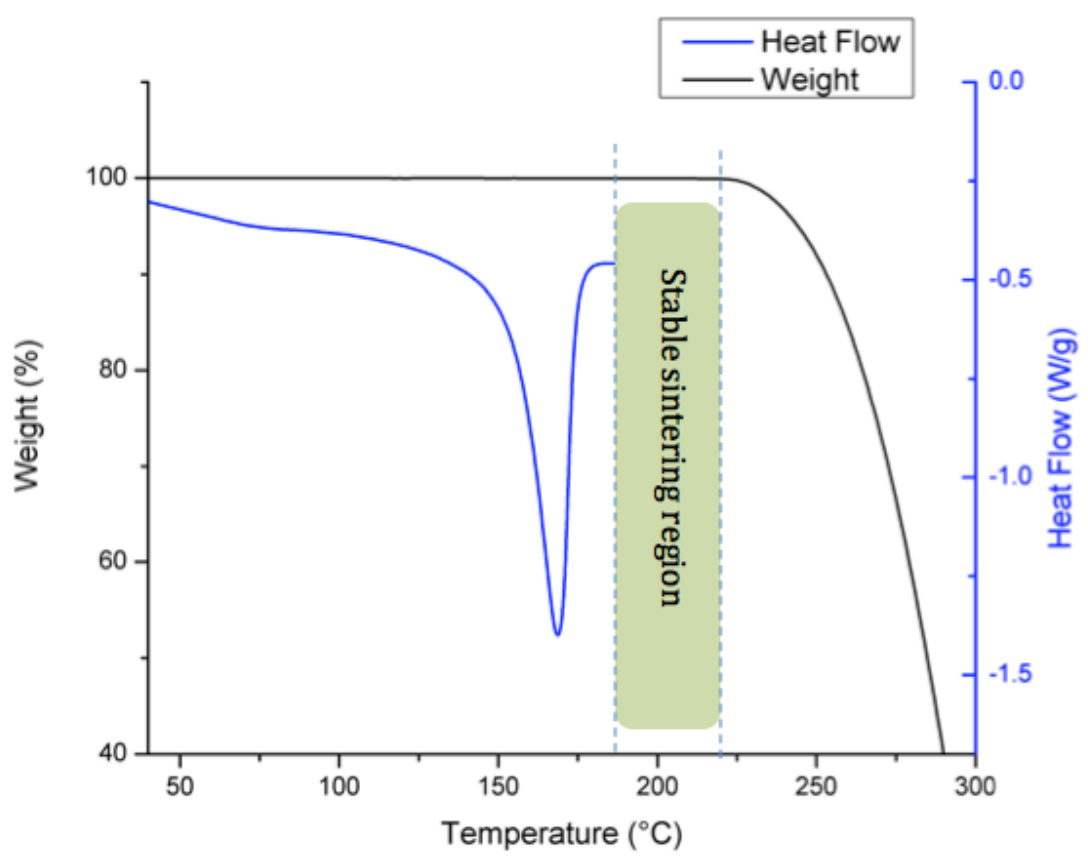

Figure 10 Stable melting region (DSC I TGA) for PP grade-B (medium MW). 


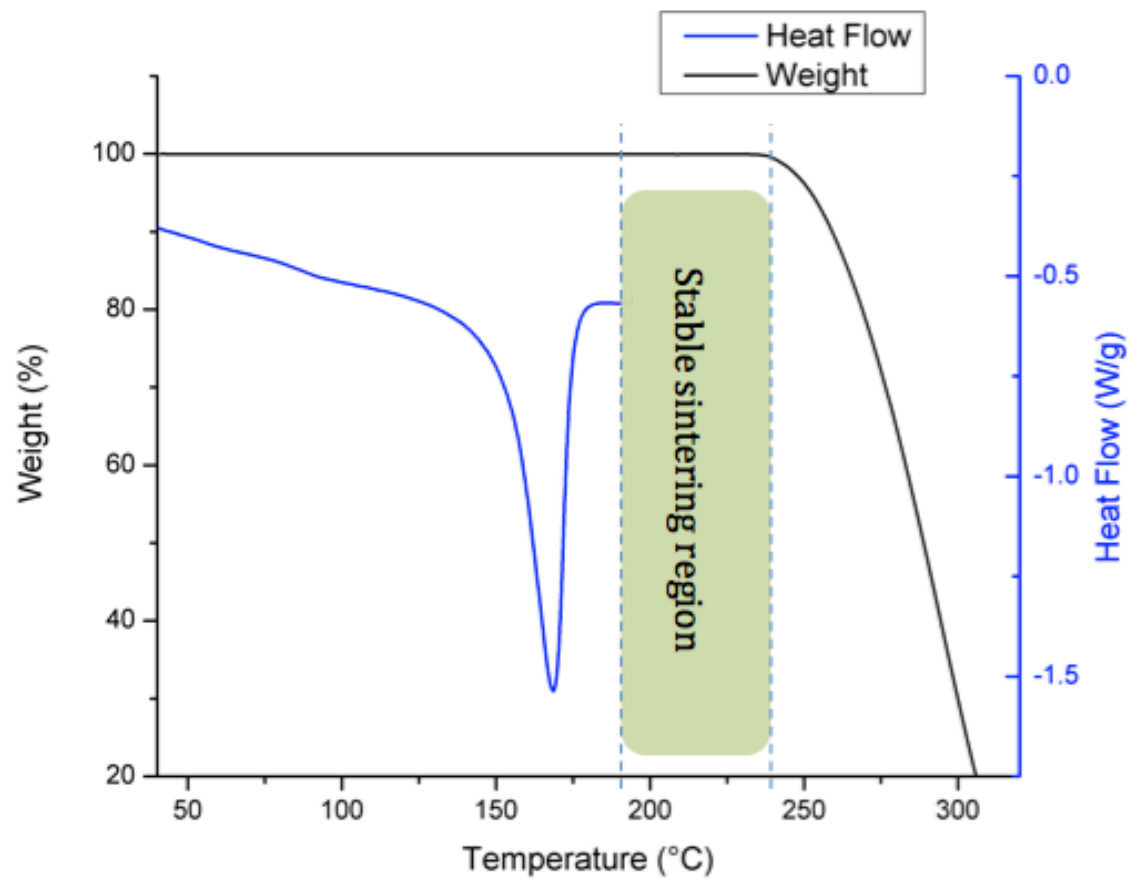

Figure 11 Stable melting region (DSC / TGA) for PP grade-C (high MW).

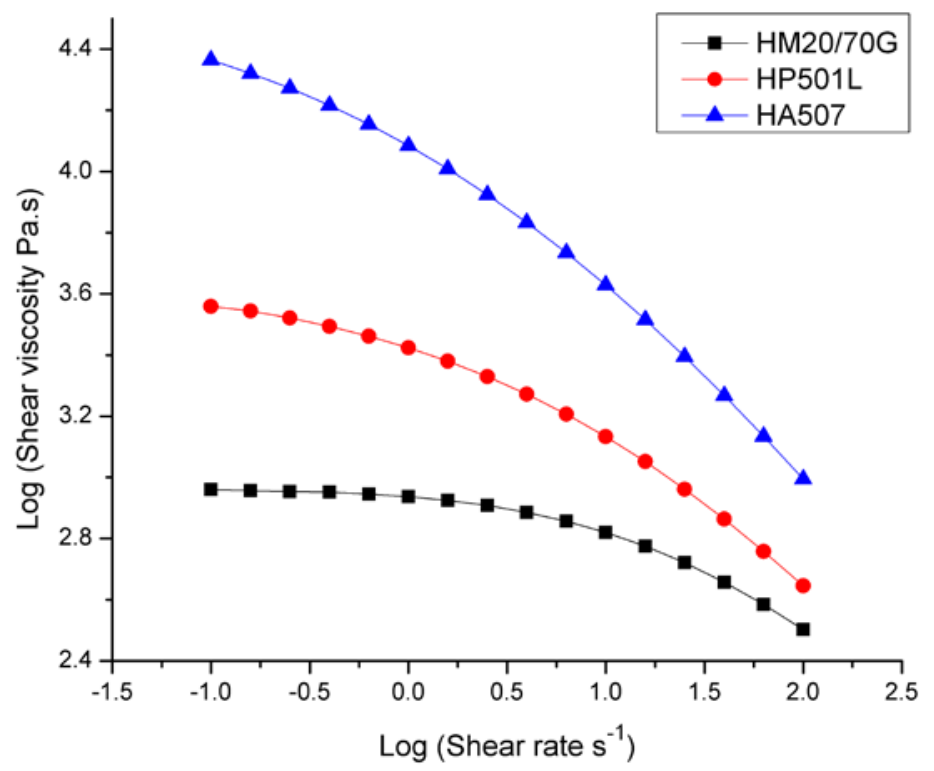

Figure 12 Rotational rheometry data - shear viscosity versus strain rate $\left(0.1-100 \mathrm{~s}^{-1}\right)$ for each PP grade 


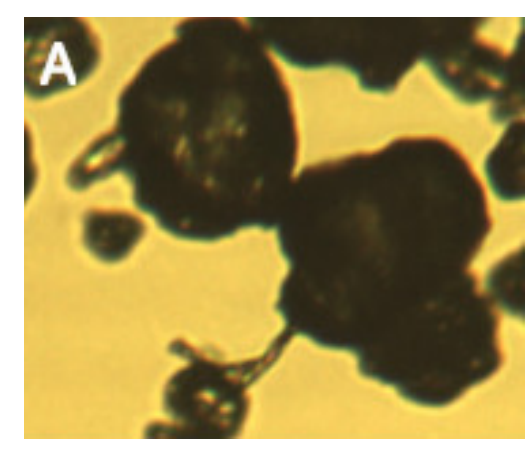

$150{ }^{\circ} \mathrm{C}$

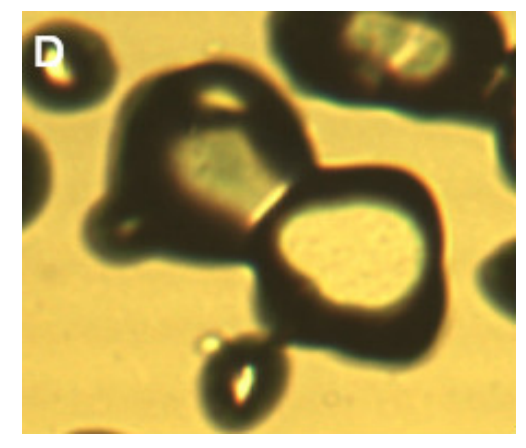

$163{ }^{\circ} \mathrm{C}$

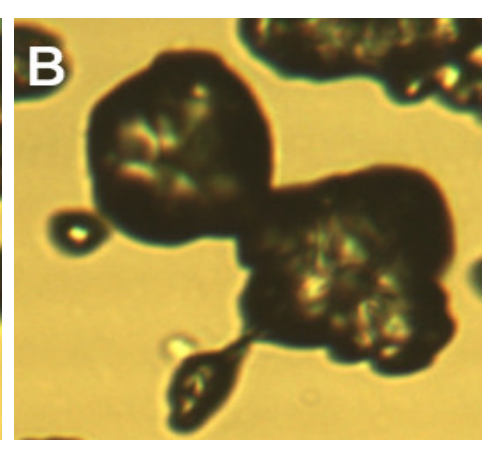

$160.5^{\circ} \mathrm{C}$

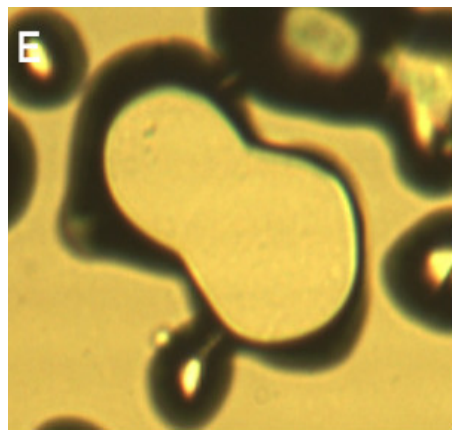

$163.8^{\circ} \mathrm{C}$

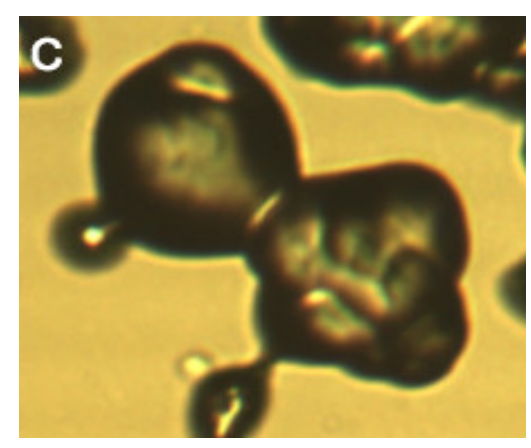

$162{ }^{\circ} \mathrm{C}$

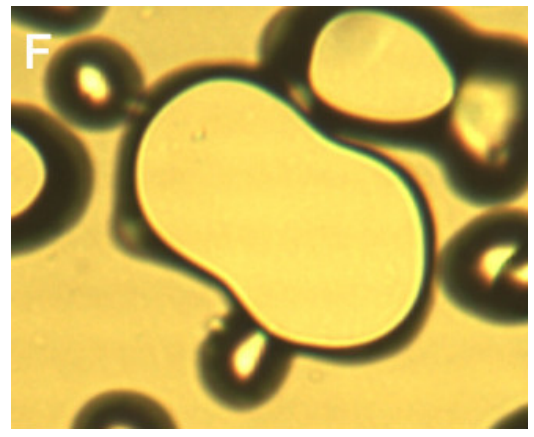

$164.6^{\circ} \mathrm{C}$

Figure 13 Images of powder melting from hot stage microscopy: PP-A (temperatures, as shown)

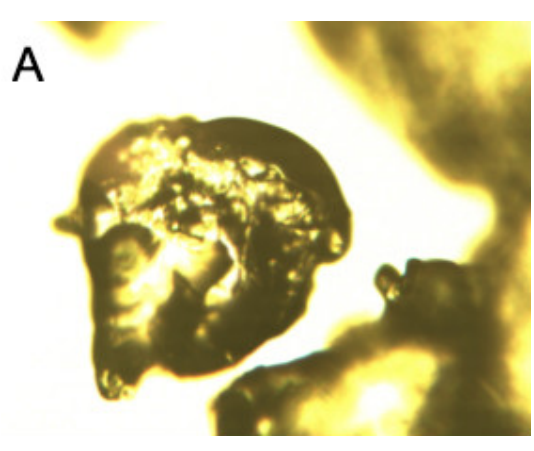

$159{ }^{\circ} \mathrm{C}$

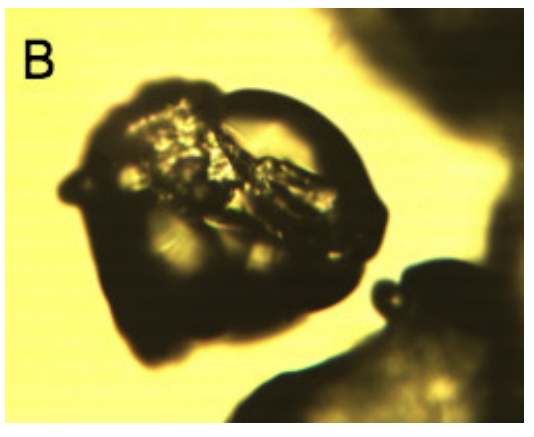

$160.8^{\circ} \mathrm{C}$

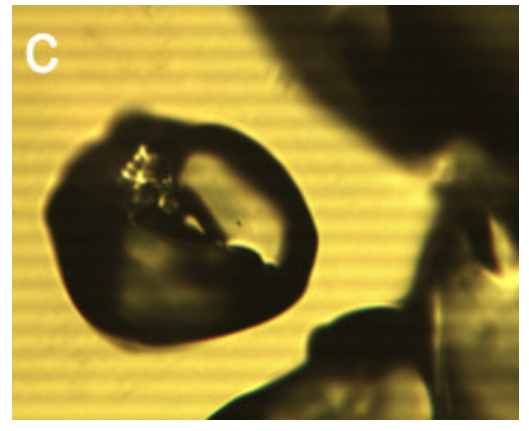

$163.3^{\circ} \mathrm{C}$

Figure 14 Images of powder melting from hot stage microscopy: PP-B (temperatures, as shown) 


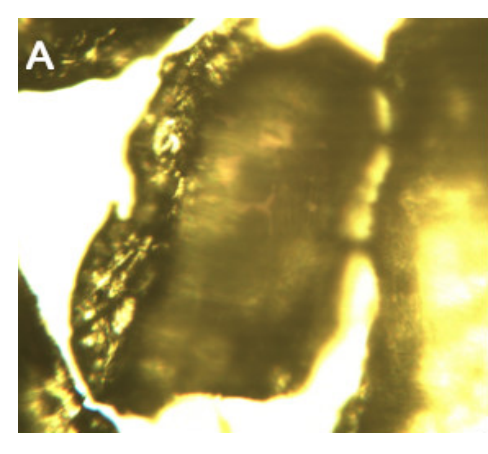

$150{ }^{\circ} \mathrm{C}$

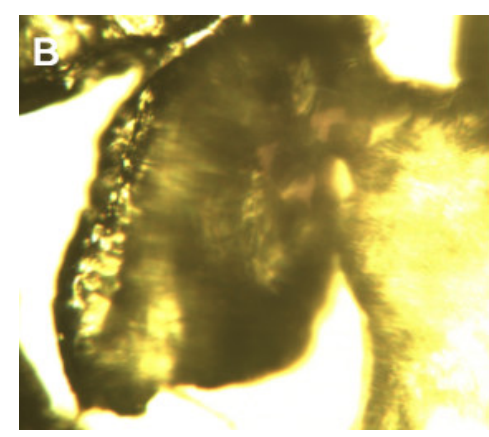

$163.6{ }^{\circ} \mathrm{C}$

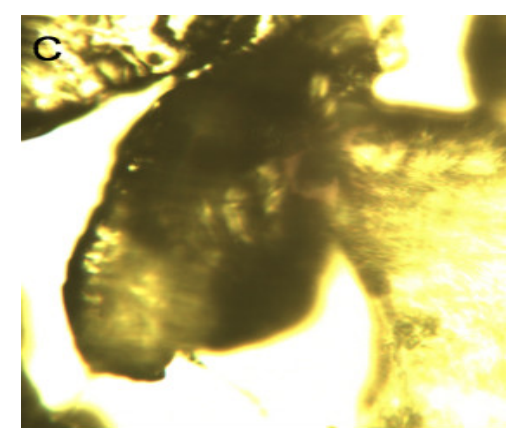

$165.3^{\circ} \mathrm{C}$

Figure 15 Images of powder melting from hot stage microscopy: PP-C (temperatures, as shown)

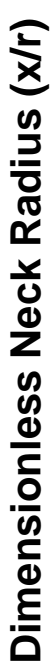
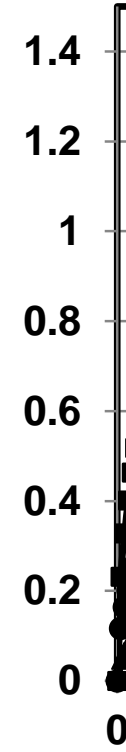
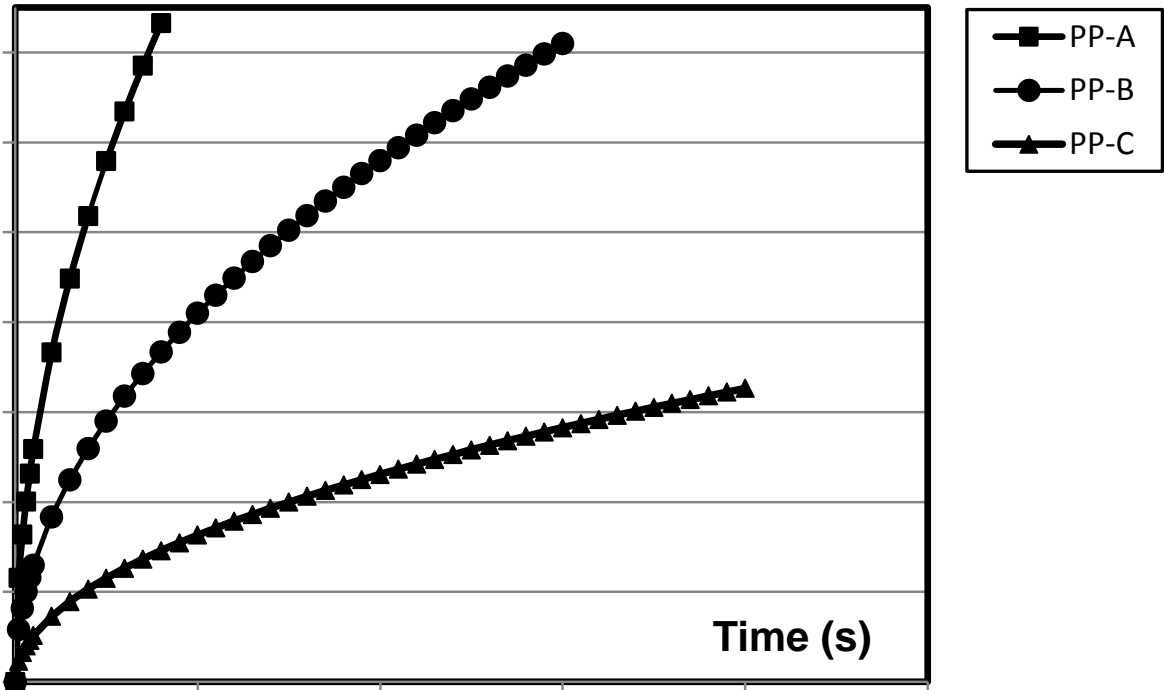

3

4

5

Figure 16 Frenkel model prediction of melting rates, for PP grades A-C, showing the effects of viscosity, induced by differences in molecular weight. 


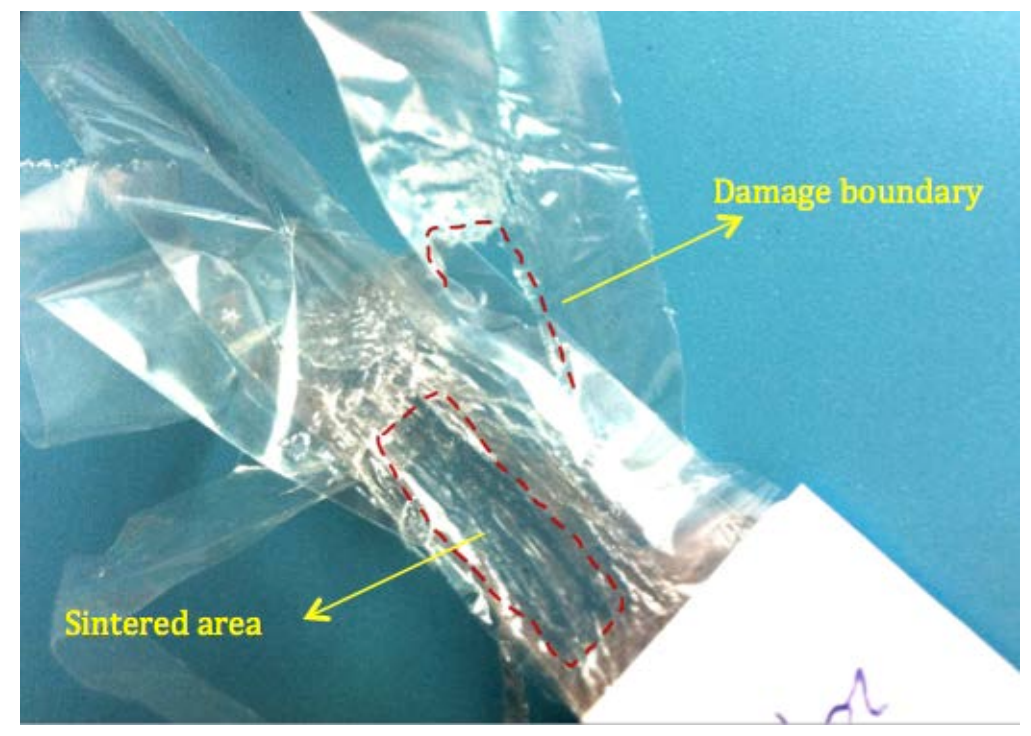

Figure 17 Example of a sintered sample (PP-B, $15 \mathrm{~mm} \mathrm{~min}^{-1}$ bed velocity, $20 \mu \mathrm{m}$ initial layer thickness)
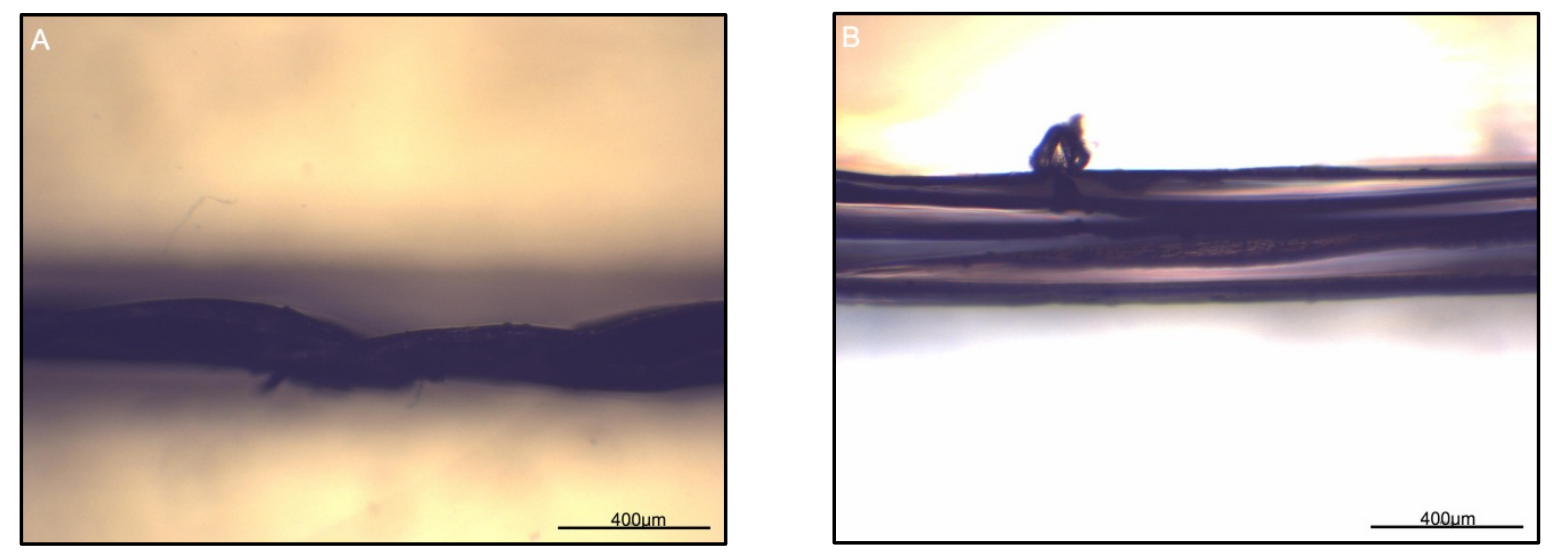

Figure 18 Images of cross-sections of sintered PP-C (high MW) 'walls' with scale bar $400 \mu \mathrm{m}$. (A: $20 \mu \mathrm{m}, 10 \mathrm{~mm} \mathrm{~min}^{-1}$; B: $20 \mu \mathrm{m}, 20 \mathrm{~mm} \mathrm{~min}{ }^{-1}$ ) 


\section{Tables}

Table 1 PP materials - physical data summary

\begin{tabular}{|l|c|c|c|c|}
\hline Material & Status & Supplier & $\begin{array}{c}\text { Melt Flow Rate } \\
\left(230{ }^{\circ} \mathrm{C} / 2.16 \mathrm{~kg}\right)\end{array}$ & $\begin{array}{c}\text { Molecular weight } \\
(\mathrm{Mw})-\text { relative }\end{array}$ \\
\hline PP-A & Fine powder & $\begin{array}{c}\text { Goonvean } \\
\text { Fibres, UK }\end{array}$ & $40 \mathrm{dg} \mathrm{\textrm {min } ^ { - 1 }}$ & Low \\
\hline PP-B & Granules & $\begin{array}{c}\text { Lyondell Basell, } \\
\text { USA }\end{array}$ & $6.0 \mathrm{dg} \mathrm{\textrm {min } ^ { - 1 }}$ & Medium \\
\hline PP-C & Granules & $\begin{array}{c}\text { Borealis, } \\
\text { Austria }\end{array}$ & $0.8 \mathrm{dg} \mathrm{min}^{-1}$ & High \\
\hline
\end{tabular}

Table 2 Extrusion conditions for PP materials

\begin{tabular}{|l|c|c|c|c|}
\hline Material & $\begin{array}{c}\text { Screw speed } \\
(\mathrm{rpm})\end{array}$ & $\begin{array}{c}\text { Haul-off velocity } \\
\left(\mathrm{m} \mathrm{min}^{-1}\right)\end{array}$ & $\begin{array}{c}\text { Pressure } \\
(\mathrm{MPa})\end{array}$ & $\begin{array}{c}\text { Tape Thickness } \\
(\mu \mathrm{m})\end{array}$ \\
\hline PP-B & 4 & 2.5 & 0.4 & 20 \\
\hline PP-B & 8 & 2.5 & 0.7 & 40 \\
\hline PP-C & 2 & 2.5 & 1.3 & 40 \\
\hline PP-C & 4 & 2.5 & 1.8 & 20 \\
\hline
\end{tabular}

Table 3 Process variables in laser melting

\begin{tabular}{|c|c|c|c|c|}
\hline Material & $\begin{array}{c}\text { Wall thickness } \\
(\mu \mathrm{m})\end{array}$ & $\begin{array}{c}\text { Laser power } \\
(\mathrm{W})\end{array}$ & $\begin{array}{c}\text { Laser power } \\
\text { 6th layer }(\mathrm{W})\end{array}$ & $\begin{array}{c}\text { Bed velocity } \\
\left(\mathrm{mm} \mathrm{min}^{-1}\right)\end{array}$ \\
\hline PP-B & 20 & $7.5 \pm 0.1$ & $7.3 \pm 0.1$ & $10 / 15 / 20$ \\
\cline { 2 - 5 } & 40 & $7.5 \pm 0.1$ & $7.3 \pm 0.1$ & $10 / 15 / 20$ \\
\hline PP-C & 20 & $7.5 \pm 0.1$ & $7.3 \pm 0.1$ & $10 / 15 / 20$ \\
\cline { 2 - 5 } & 40 & $7.5 \pm 0.1$ & $7.3 \pm 0.1$ & $10 / 15 / 20$ \\
\hline
\end{tabular}


Table 4

DSC data for PP (endothermic heating / exothermic cooling processes)

\begin{tabular}{|l|c|c|c|c|}
\hline \multicolumn{1}{|c|}{ Sample } & Melt peak $\left({ }^{\circ} \mathrm{C}\right)$ & $\begin{array}{c}\text { Melt enthalpy } \\
\left(\mathrm{J} \mathrm{g}^{-1}\right)\end{array}$ & $\begin{array}{c}\text { Tangent melting } \\
\text { point }\left({ }^{\circ} \mathrm{C}\right)\end{array}$ & $\begin{array}{c}\text { Crystallinity } \\
(\%)\end{array}$ \\
\hline PP-A & 168 & 103 & 151 & 49.3 \\
\hline PP-B & 169 & 84.3 & 155 & 40.3 \\
\hline PP-C & 168 & 90.3 & 153 & 43.2 \\
\hline
\end{tabular}

\begin{tabular}{|l|c|c|c|c|}
\hline \multicolumn{1}{|c|}{ Sample } & $\begin{array}{c}\text { Crystallisation } \\
\text { peak }\left({ }^{\circ} \mathrm{C}\right)\end{array}$ & $\begin{array}{c}\text { Crystallisation } \\
\text { enthalpy }\left(\mathrm{J} \mathrm{g}^{-1}\right)\end{array}$ & $\begin{array}{c}\text { Crystallisation } \\
\text { temperature } \\
\text { (tangent) }\left({ }^{\circ} \mathrm{C}\right)\end{array}$ & $\begin{array}{c}\text { Crystallinity } \\
(\%)\end{array}$ \\
\hline PP-A & 112 & 93.0 & 117 & 44.5 \\
\hline PP-B & 112 & 95.1 & 117 & 45.5 \\
\hline PP-C & 119 & 110.1 & 123 & 52.6 \\
\hline
\end{tabular}

Table 5 Stable sintering region (SSR) for the PP samples

\begin{tabular}{|l|c|c|c|}
\hline Sample & $\begin{array}{c}\text { Lower temperature } \\
\text { limit } \\
\left({ }^{\circ} \mathrm{C}\right)\end{array}$ & $\begin{array}{c}\text { Upper temperature } \\
\text { limit } \\
\left({ }^{\circ} \mathrm{C}\right)\end{array}$ & $\begin{array}{c}\text { SSR range: } \\
\mathrm{PP} \\
\left({ }^{\circ} \mathrm{C}\right)\end{array}$ \\
\hline PP-A & 178 & 210 & 32 \\
\hline PP-B & 180 & 220 & 40 \\
\hline PP-C & 180 & 240 & 40 \\
\hline
\end{tabular}

Table 6 Oxidation Induction Time (OIT) data for PP at $240^{\circ} \mathrm{C}$

\begin{tabular}{|l|c|c|}
\hline Material & $\begin{array}{c}\text { Molecular } \\
\text { weight (Mw) - } \\
\text { relative }\end{array}$ & $\begin{array}{c}\text { OIT } \\
\text { (min.) }\end{array}$ \\
\hline PP-A & Low & 0.93 \\
\hline PP-B & Medium & 1.05 \\
\hline PP-C & High & 1.03 \\
\hline
\end{tabular}


Table 7 Power law $(k, n)$ and Cross model $\left(\eta_{0}, \tau^{*}\right)$ constants for PP materials

\begin{tabular}{|l|c|c|c|c|}
\hline Sample & $\mathrm{n}$ & $\begin{array}{c}\mathrm{k} \\
\left(\mathrm{Ns}^{\mathrm{n}} \mathrm{m}^{-2}\right)\end{array}$ & $\begin{array}{c}\mathrm{\eta}_{0} \\
(\mathrm{~Pa} . \mathrm{s})\end{array}$ & $\begin{array}{c}\tau^{*} \\
\left(\mathrm{~N} \mathrm{~m}^{-2}\right)\end{array}$ \\
\hline PP-A & 0.68 & 1,413 & 910 & $0.53 \times 10^{4}$ \\
\hline PP-B & 0.51 & 4,266 & 3,631 & $0.67 \times 10^{4}$ \\
\hline PP-C & 0.37 & 18,621 & 22,909 & $1.47 \times 10^{4}$ \\
\hline
\end{tabular}

Table 8 Results from peel testing of sintered ' walls': effects of bed velocity, layer thickness and polymer type

\begin{tabular}{|c|c|c|c|c|}
\hline \multirow{2}{*}{\multicolumn{2}{|c|}{$\begin{array}{c}\text { Sample \& } \\
\text { Layer thickness }(\mu \mathrm{m})\end{array}$}} & \multicolumn{3}{|c|}{$\begin{array}{l}\text { Bed velocity } \\
\left(\mathrm{mm} \mathrm{min}^{-1}\right)\end{array}$} \\
\hline & & 10 & 15 & 20 \\
\hline PP-A & $20 \mu \mathrm{m}$ & $\bar{Y}$ & $\mathrm{Y}$ & $X$ \\
\hline PP-A & $40 \mu \mathrm{m}$ & -- & -- & $\bar{Y}$ \\
\hline PP-B & $20 \mu \mathrm{m}$ & $\mathrm{Y}$ & $\mathrm{Y}$ & $X$ \\
\hline PP-B & $40 \mu \mathrm{m}$ & -- & -- & X \\
\hline
\end{tabular}

